\title{
ANALYSIS OF TRANSPORT MECHANISMS IN DENSE FUEL DROPLET SPRAYS
}

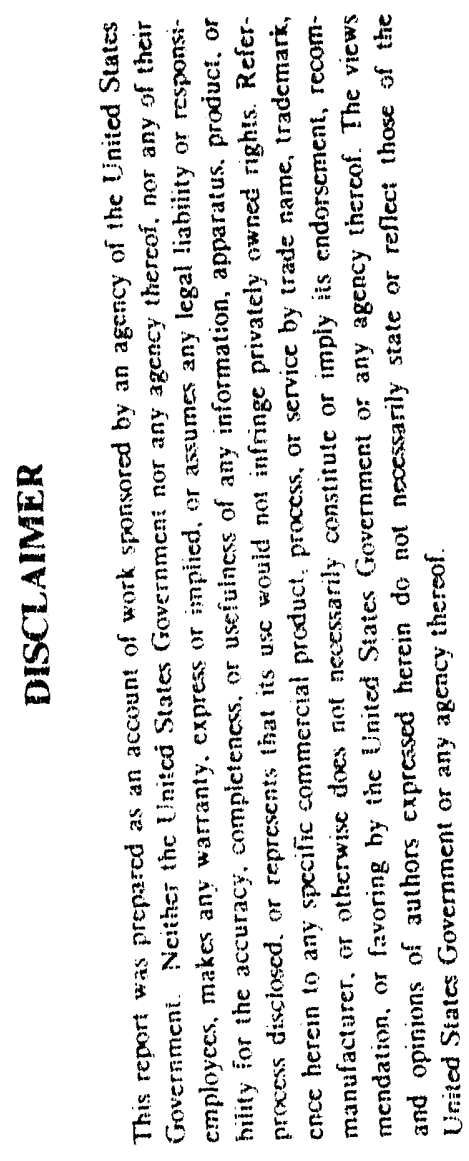

\section{Final Report} \\ C. Kleinstreuer \\ NC State University \\ Raleigh, North Carolina 27695-7910
}

May 1991

PREPARED FOR THE U. S. DEPARTMENT OF ENERGY UNDER GRANT NUMBER DE-FG-05-87ER 13728 


\title{
COMPUTATIONAL ANALYSIS OF INTERACTING VAPORIZING FUEL DROPLETS*
}

\author{
C. Kleinstreuer \\ Deparment of Mechanical and Aerospace Engineering \\ North Carolina State University \\ Raleigh, NC 27695-7910
}

\begin{abstract}
ABSTRAC
This report deals with fundamental numerical analyses of the fluid mechanics, heat transfer, mass transfer and particle dynamics of interacting spheres and vaporizing droplets in a linear array or on a one dimensional trajectory. A generally available finite element software package has been modified and extended to solve several case studies including (1) closelyspaced monodisperse spheres with or without blowing; (2) closely-spaced vaporizing fuel droplets; and (3) dynamically interacting vaporizing fuel droplets on a one-dimensional trajectory. Axisymmetric laminar flow, $10 \leq$ Red $\leq 200$, has been assumed for three statically or dynamically interacting spherical solids and vaporizing droplets.
\end{abstract}

The emphasis in this work is on the evaluation of the effects of key system parameters, such as free stream Reynolds number, interparticle spacings, liquid/gas-phase viscosity ratio and variable fluid properties, on the interfacial transfer processes and, ultimately, on the particle Nusselt number, vaporization rate and drag coefficient. As a result, computer-generated correlations between integral quantities and system parameters have been postulated for blowing spheres and vaporizing droplets.

In addition to the initial Reynolds number and droplet spacings, variable fluid properties, liquid-phase heating and internal droplet circulation have a very strong effect on the dynamic behavior of multi-droplet systems. While the lead droplet is most significantly affected by all key parameters, the presence of the second and third droplet causes distinct interaction effects which are largely dependent upon the initial droplet spacings.

Applications of these base case studies include spherical-structure/fluid-flow interactions, as well as interacting vaporizing droplets in different sprays related to propulsion systems, irrigation, spray coating, etc. Focusing on fuel droplet sprays, results of the dynamic multidroplet study can assist in better atomizers and combustion chamber designs which may lead to improved combustion efficiencies, smaller/lighter systems, and reduced pollutant emissions.

\footnotetext{
"The assistance of Dr. H. Chiang on this report is gratefully acknowledged.
} 
radius of droplet

$c_{p}$ heat capacity

$C_{D}^{k} \quad$ drag coefficient of droplet $k$

$C_{D, s} \quad$ single sphere drag coefficient

$d$ droplet diameter

$\mathcal{D}$ dimensionless interdroplet distances, $d_{i j}=d_{i j}^{*} / d_{0}^{*}$

$k$ diffusion coefficient

L latent heat of vaporization

Le Lewis number, $\mathrm{Sc} / \mathrm{Pr}$

$m \quad$ mass

M molecular weight

$N u \quad$ Nusseit number, $h d^{*} / k$

$p \quad$ pressure

Pr Prandtl number, $\nu / \alpha$

$\mathrm{Pe} \quad$ Peclet number, $\mathrm{Re} \mathrm{Pr}$

$q_{h}^{\prime \prime} \quad$ dimensionless interfacial heat flux

$q_{m}^{\prime \prime} \quad$ dimensionless interfacial mass flux

$r \quad$ radial spherical coordinate

$R \quad$ radial cylindrical courdinate; gas constant

$\operatorname{Re}_{o} \quad$ initial Reynolds number. $u_{o}^{*} d_{o}^{*} / \nu_{r}$

$\operatorname{Re}_{m} \quad$ instantaneous Reynolds nurnber, $u_{\infty}^{*} d^{*} \rho_{\infty} / \mu_{f}$

Sc Schmidt number, $\nu / \mathcal{D}$

Sh Sherwood number. $h d_{o}^{*} / \rho \mathcal{D}$

$t$ time

$T \quad$ temperature

$\Delta T \quad$ initial temperature difference, $T_{\infty}-T_{0}$

$\vec{v} \quad$ velocity vector 


$\begin{array}{ll}u_{b} & \text { uniform blowing velocity } \\ u_{n}, v_{n} & \text { normal or local blowing velocity } \\ u_{t}, v_{t} & \text { tangential components } \\ u, v & \text { velocity components } \\ u_{\infty} & \text { instantaneous free stream velocity } \\ u_{0} & \text { initial free stream velocity } \\ \forall & \text { volume, variable } \\ X & \text { mole fraction } \\ Y & \text { mass fraction }\end{array}$

\section{Greek Symbols}

$\begin{array}{ll}\alpha & \text { thermal diffusivity; drag coefficient ratio, } d_{k}=C_{D}^{(k)} / C_{D s} \\ \nu & \text { kinematic viscosity } \\ \mu & \text { dynamic viscosity } \\ \kappa & \text { weighing factor } \\ \theta & \text { spherical coordinate } \\ \rho & \text { density } \\ \tau & \text { dimensionless time, } t u_{o}^{*} / d_{o}^{*} \\ \tau_{s} & \text { surface shear stress } \\ \xi & \text { density ratio } \\ \eta & \text { beat capacity ratio } \\ \chi & \text { dynamic viscosity ratio } \\ \lambda & \text { thermal conductivity ratio } \\ \omega & \text { mass diffusivity ratio }\end{array}$

\section{Subscripts}

$\begin{array}{ll}a(\operatorname{air} 1) 1 & \text { air } \\ b & \text { surface blowing } \\ b p & \text { boiling point } \\ c & \text { critical }\end{array}$




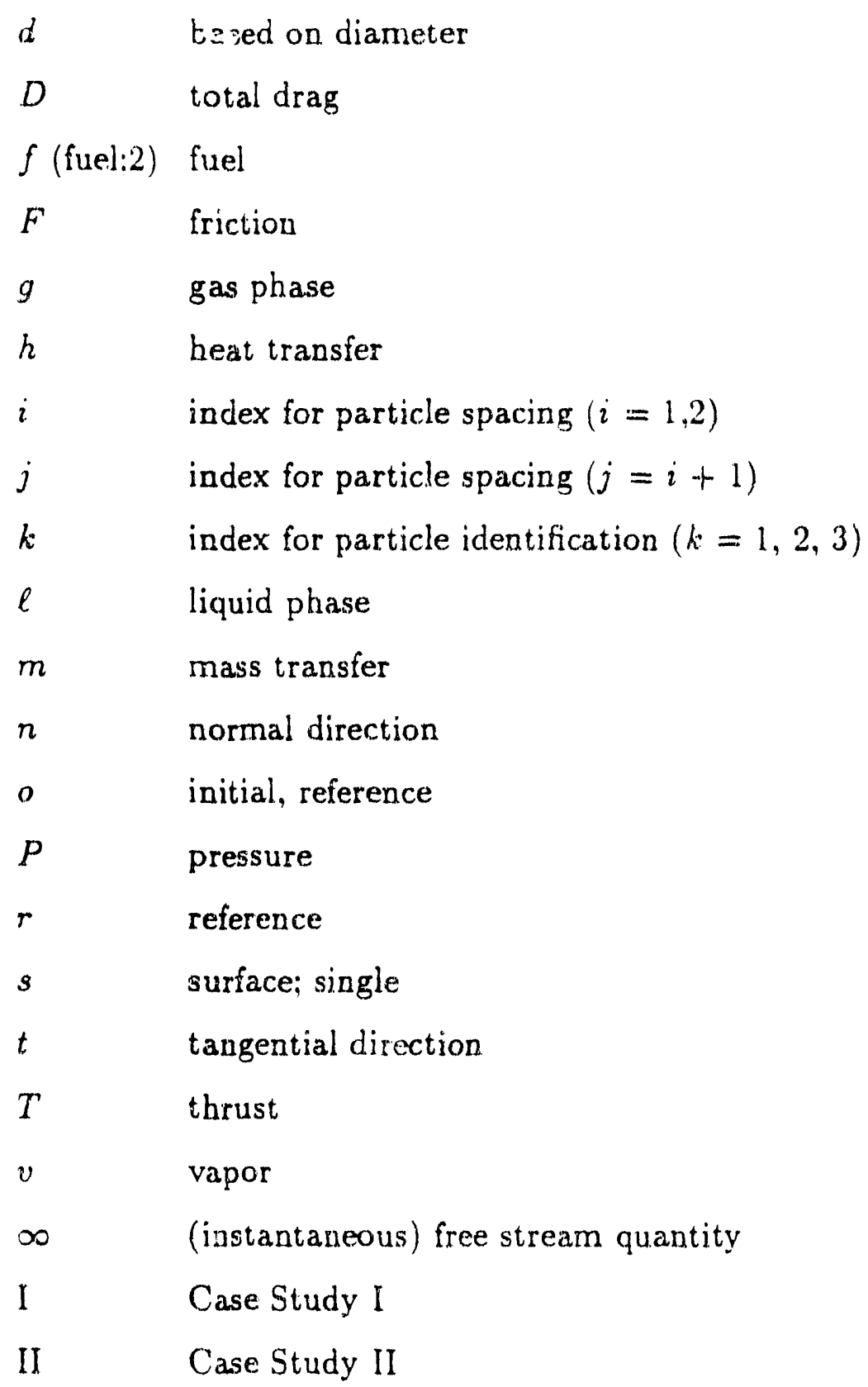

\section{Superscripts}

(k) index for particle identification $(k=1,2,3)$

dimensional quantities 


\section{INTRODUCTION}

The transient dynamics and transfer processes of interacting vaporizing droplets on a onedimensional trajectory form a base case for studying highly coupled nonlinear effects important in dense sprays, particularly in droplet spray combustion (cf. Dwyer, 1989; Faeth, 1987; Law, 1984; or Sirignano, 1983). Some of the more significant parameters affecting irlterfacial transport phenornena in this two-phase flow problem are the initial gas/liquid-phase temperature differences, relative droplet spacings and variable fluid properties.

Traditionally, fluid properties are evaluated at "constant" reference temperatures, e.g., $T_{\text {ref }}=T_{s}+\kappa\left(T_{\infty}-T_{s}\right)$ where $0.19 \leq \kappa \leq 0.50$, which implies that the Lewis number stays constant, near unity. However, for accurate calculations of the droplet Nusselt number and Sherwood number, it is necessary to update all fluid properties as a function of the local temperature and/or species concentration, especially for vapors with high molecular weights. The influence of variable fluid properties in detailed numerical analyses has been partially addressed by Haywood et al. (1989) and Chiang et al. (1989). The close resemblance between the isotherms and mass fraction contours (i.e., Le $\approx 1$ ) given by Haywood et al. (1989) actually do not show the different scales of diffusion for heat and mass transfer even at low droplet surface temperatures. The impact of relative particle spacing was demonstrated in previous contributions considering fixed linear arrays of blowing spheres (cf. Chiang \& Kleinstreuer, 1991a) and vaporizing droplets (cf. Chiang \& Kleinstreuer, 1991b). In this paper, the dynamics and transfer mechanisms of thrce interacting vaporizing droplets on a one-dimensional trajectory are analyzed. The closest contribution to this topic is the paper by Raju \& Sirignano (1990) who considered two droplets in tandem. However, at least three particles are necessary to simulate interaction effects more realistically. The experimental paper by Rowe \&. Henwood (1961), the flow visualizations by Tsuji et al. (1982), and the drag coefficient correlations by Mulholland et al. (1988) for water drops are three examples of the very few and incomplete experimental papers devoted to interacting spherical particles.

In summary, a detailed computer simulation of interacting evaporating (heavy) fuel droplets with variable fluid properties is necessary for the accurate and comprehensive anal- 
ysis of the individual droplet's total drag, Nusseit number and Sherwood number. These global parameter distributions together with the instantaneous relative droplet locations, sizes and velocities are important in spray system design applications (cf. Clift et al., 1978; Kuo, 1986; or Law, 1990) and for less computer-intensive approximate analyses (cf. Kleinstreuer and Wang, 1990). Additional references are given in the body of the text.

\section{ANALYSIS}

Considering three spherical droplets decelerating and evaporating on a one-dimensional trajectory in a high-temperature. dry-air environment. the gas-phase momentum, heat and mass transfer equations are coupled with the liquid-phase momentum and heat transfer equations via the interfacial compatibility conditions. Thermal radiation, buoyancy and thermo-diffusion effects are neglected. Thus the dimensionless equations for axisymmetric thermal flow with variable fluid properties can be written as follows (cf. Fig. 1).

\section{Gas Phase:}

$$
\begin{gathered}
\nabla \cdot\left(\xi_{g} \vec{v}_{g}\right)=0 \\
\xi_{g}\left(\frac{\partial}{\partial \tau}+\vec{v}_{g} \cdot \nabla\right) \vec{v}_{g}=-\nabla p_{g}+R e_{g}^{-1} \nabla \cdot\left(\chi_{g} \nabla \vec{v}_{g}\right) \\
\xi_{g} \eta_{g}\left(\frac{\partial}{\partial \tau}+\vec{v}_{g} \cdot \nabla\right) T_{g}=P e_{h_{, g}}^{-1} \nabla \cdot\left(\lambda_{g} \nabla T_{g}\right)+\xi_{g}\left(\frac{c_{p, v}-c_{p, a}}{c_{p \infty}}\right) P e_{m, g}^{-1} \omega_{g}\left(\nabla T_{g} \cdot \nabla Y_{g}\right) \\
\xi_{g}\left(\frac{\partial}{\partial \tau}+\vec{v}_{g} \cdot \nabla\right) Y_{g}=P e_{m, g}^{-1} \nabla \cdot\left(\xi_{g} \omega_{g} \nabla Y_{g}\right)
\end{gathered}
$$


and

\section{Liquid Phase:}

$$
\begin{gathered}
\nabla \cdot\left(\xi_{\ell} \vec{v}_{\ell}\right)=0 \\
\xi_{\ell}\left(\frac{\partial}{\partial \tau}-\vec{v}_{\ell} \cdot \nabla\right) \vec{v}_{\ell}=-\nabla p_{\ell}+R e_{\ell}^{-1} \nabla \cdot\left(\chi_{\ell} \nabla \vec{v}_{\ell}\right) \\
\xi_{\ell} \eta_{\ell}\left(\frac{\partial}{\partial \tau}+\vec{v}_{\ell} \cdot \nabla\right) T_{\ell}=P e_{h, \ell}^{-1} \nabla \cdot\left(\lambda_{\ell} \nabla T_{\ell}\right)
\end{gathered}
$$

where

$$
\begin{gathered}
\vec{v}=\vec{v} / u_{o}^{*}, \quad p=p^{*} /\left(\rho_{\infty} u_{o}^{* 2}\right), \quad T=T^{*} / T_{\infty}^{*}, \quad \nabla=\nabla^{*} / d_{o}^{*}, \quad \tau=t^{*} u_{o}^{*} / d_{o}^{*}, \\
\xi=\rho / \rho_{r}, \quad \eta=c_{p} / c_{p, r}, \quad \chi=\mu / \mu_{r}, \quad \lambda=k / k_{r}, \quad \omega=\mathcal{D} / \mathcal{D}_{r}, \\
R e_{o}=u_{o}^{*} d_{o}^{*} / \nu_{r}, \quad P e_{h}=u_{o}^{*} d_{o}^{*} / \alpha_{r} \quad \text { and } \quad P e_{m}=u_{o}^{*} d_{o}^{*} / \mathcal{D}_{r} \quad(8 a-m)
\end{gathered}
$$

The reference fluid properties are evaluated at the free-stream conditions for the gasphase parameters; for the liquid phase, the initial droplet temperature is chosen as reference. The second term on the R.H.S. of equation (3) is the interdiffusion term which represents the net enthalpy effect between fuel vapor and dry air.

The fixed origin of the axisymmetric coordinates $(R, Z)$ is located at the center of the first droplet. The gas flow field, a cylindrical domain, is evaluated separately from the liquid-phase, i.e., the spherical domain. Coupling of the two fluid flow fields at each time step is described below. Initially, at $\tau=0$ when the droplet has been injected into the high-temperature armbient, a gas-phase velocity, temperature and vapor concentration field has been created while the liquid-phase is stagnant and at its initial temperature. At the domain inlet

$$
u_{g}=1, \quad v_{g}=0, \quad T_{g}=1 \quad \text { and } \quad Y_{g}=0
$$


Because of symmetry, all gradients at the centerline $(R=0)$ are equal to zero. The extent of the computational domain, being a function of the free-stream Reynolds number (cf. Chiang and Kleinstreuer, 1991a), is large enough so that all appropriate outer boundary and outlet gradients are identical zero.

\section{Interfacial Conditions}

Both phases are coupled via the interfacial conditions representing conservation of mass, moment $1 \mathrm{~m}$ and energy. Specifically, continuous velocities, shear stress and temperature are required at the gas-liquid boundaries.

$$
u_{t, g}=u_{t, \ell} \quad \tau_{s, g}=\left(\frac{\rho_{o, \ell}}{\rho_{\infty, g}}\right) \tau_{s, \ell} \quad \text { and } \quad T_{s, g}=T_{s, \ell} \quad(10 a-c)
$$

where

$$
\tau_{s}=\left.\frac{\chi}{R e} \frac{\partial u}{\partial r}\right|_{r=a(\tau)} .
$$

The normal interfacial velocity, i.e., the vapor blowing velocity, is proportional to the dimensionless diffusion mass flux.

$$
u_{n, g}=\frac{1}{1-Y_{s}} q_{m, g}^{\prime \prime}=-\left.\frac{1}{1-Y_{s}}\left(\frac{\omega_{g}}{P e_{m, g}} \frac{\partial Y}{\partial r}\right)\right|_{\mathrm{r}=a(\tau)}
$$

where $Y$, is the vapor concentration at the droplet surface assuming thermodynamic equilibrium.

$$
Y_{s}=\frac{M_{v} X_{s}}{M_{v} X_{s}+M_{a}\left(1-X_{s}\right)}
$$

where the interfacial mole fraction

$$
X_{s}=p_{v, a}\left(T_{s}\right) / p_{a}
$$

The heat transferred from the gas stream divides up into liquid droplet heating and latent heat of vaporization.

$$
q_{h, g}^{\prime \prime}=\gamma q_{h, \ell}^{\prime \prime}+\frac{\xi_{g}}{1-Y_{s}} \frac{c_{p \infty, g} T_{\infty}}{L\left(T_{s}\right)} q_{m, g}^{\prime \prime}
$$

where

$$
\gamma=\frac{\rho_{o, \ell} c_{p o, \ell}}{\rho_{\infty, g} c_{p \infty, g}}, \quad q_{h}^{\prime \prime}=-\left.\lambda P e_{h}^{-1} \frac{\partial T}{\partial r}\right|_{\Gamma=a(r)}
$$


and

$$
q_{m}^{\prime \prime}=-\left.\omega P e_{m}^{-1} \frac{\partial Y}{\partial r}\right|_{\mathrm{r}=a(\tau)}
$$

\section{Auxiliary Conditions}

Assuming spherical droplets at all times, the decrease in each droplet radius with time, or shrinkage, can be expressed as

$$
\frac{d a^{(k)}}{d \tau}=\frac{\rho_{g}}{2 \rho_{\ell}} \int_{0}^{\pi} u_{n, g}^{(k)} \sin \theta d \theta
$$

where the superscript $k$ identifies each droplet, i.e., $k=1,2,3$.

The deceleration of each droplet due to the gas phase drag force can be described by Newton's 2nd law of motion as,

$$
m^{(k)} \frac{d u_{\infty}^{*(k)}}{d t^{*}}=-\frac{\pi\left(a^{*(k)}\right)^{2}}{2} \rho_{\infty, 9}\left(u_{\infty}^{*(k)}\right)^{2} \hat{C}_{D}^{(k)}
$$

Nondimensionalization yields

$$
\frac{d u_{\infty}^{(k)}}{d \tau}=-\frac{3}{8}\left(\frac{\rho_{\infty, g}}{\bar{\rho}_{\ell}^{(k)}}\right)\left(\frac{a_{o}}{a^{(k)}(\tau)}\right)\left(u_{\infty}^{(k)}\right)^{2} \hat{C}_{D}^{(k)}
$$

where $\hat{C}_{D}^{(k)}$ is the drag coefficient of droplet $k$ based on the instantaneous droplet velocity, $u_{\infty}^{(k)}$. For convenience, the initial droplet injection speed, $u_{o}^{*}$, should be employed, where $\hat{C}_{D}^{(k)} / u_{0}^{* 2}=C_{D}^{(k)} /\left(u_{\infty}^{m(k)}\right)^{2}$. Thus,

$$
\frac{d u_{\infty}^{(k)}}{d \tau}=-\frac{3}{8}\left(\frac{\rho_{\infty . g}}{\bar{\rho}_{\ell}^{(k)}}\right)\left(\frac{a_{\circ}}{a^{(k)}(\tau)}\right) C_{D}^{(k)}
$$

where $\bar{\rho}^{(k)} \approx \rho_{o, \ell}$ for simplicity and $C_{D}^{(k)}$ is discussed below.

In the Eulerian frame chosen, the free stream gas flow approaches the leading droplet with a velocity of $u_{\infty}=-u_{\infty}^{(1)}$. Since each droplet is subjected to a different drag force, the instantaneous velocity of each droplet can be written as,

$$
u_{\infty}^{(k)}=\tilde{u}_{\infty}^{(k)}+\Delta u^{(k)} ; \quad k=1,2,3
$$


which is obtained from equation (15c) after integration. Velocities $u_{\infty}$ and $\tilde{u}_{\infty}$ are evaluated at the new and previous time steps, respectively, and $\Delta u$ is the velocity variation during the time increment.

The velocity of the $2 \mathrm{nd}$ droplet with respect to the leading droplet is

$$
\begin{aligned}
u_{21} & =u_{\infty}^{(2)}-u_{\infty}^{(1)} \\
& =\left(\tilde{u}_{\infty}^{(2)}+\Delta u^{(2)}\right)-\left(\tilde{u}_{\infty}^{(1)}+\Delta u^{(1)}\right) \\
& =\left(\tilde{u}_{\infty}^{(2)}-\tilde{u}_{\infty}^{(1)}\right)+\left(\Delta u^{(2)}-\Delta u^{(1)}\right) \\
& =\tilde{u}_{21}+\Delta u_{21}
\end{aligned}
$$

Similarly for the 3 rd droplet

$$
\begin{aligned}
u_{31} & =u_{\infty}^{(3)}-u_{\infty}^{(1)} \\
& =\tilde{u}_{31}+\Delta u_{31}
\end{aligned}
$$

The motions of the 2 nd and 3 rd droplets relative to the leading droplet must show their effect on the entire gas flow field. Hence, the modifications of the boundary conditions are:

$$
\begin{gathered}
v_{n}^{(k)}=u_{n}^{(k)}+u_{k 1} \cos \theta \\
v_{t}^{(k)}=u_{t}^{(k)}-u_{k 1} \sin \theta \quad k=2,3
\end{gathered}
$$

Here, $u_{n}$ and $u_{t}$ are the liquid-phase surface blowing velocity and tangential velocity, respectively, while $v_{n}$ and $v_{t}$ are the modified boundary conditions required for the 2 nd and 3 rd droplet. The relationship of these velocities are shown in Fig. 1.

\section{Fluid Property Correlations}

The transport properties of the gas-vapor mixture usually vary with the local mole fraction (cf. Wilke, 1950)

$$
\begin{aligned}
& \mu=X_{1} \mu_{1} /\left(X_{1}+C_{1} X_{2} \phi_{12}\right)+X_{2} \mu_{2} /\left(X_{2}+C_{1} X_{1} \phi_{21}\right) \\
& k=X_{1} k_{1} /\left(X_{1}+C_{2} X_{2} \phi_{12}\right)+X_{2} k_{2} /\left(X_{2}+C_{2}^{\prime} X_{1} \phi_{21}\right)
\end{aligned}
$$

where

$$
X_{1}=\frac{Y M_{a}}{Y M_{a}+(1-Y) M_{v}}, \quad X_{2}=\left(1-X_{1}\right), \quad C_{1}=1, \quad C_{2}=1.065
$$


and

$$
\left.\phi_{i j}=\left[1+M_{j} / M_{i}\right)^{1 / 4}\left(\mu_{i} / \mu_{j}\right)^{1 / 2}\right]^{2}\left(8+8 M_{i} / M_{j}\right)^{-1 / 2} ; \quad i=j=1 \cong \text { fuel and } 2 \cong \text { air }
$$

The thermodynamic properties of the gas-vapor mixture are more likely dependent upon the local mass fraction, i.e.,

$$
\rho_{g}=\left[\frac{Y}{\rho_{v}}+\frac{(1-Y)}{\rho_{a}}\right]^{-1}
$$

and

$$
C_{p, g}=Y C_{p, v}+(1-Y) C_{p, a}
$$

The interfacial fluid properties $\left(p_{v}, L, c_{p}, \rho, k, \mu\right.$ and $\left.\mathcal{D}\right)$ are curve-fitted (cf. Yaw, 1977) using the data sets given by Vargaftik (1975) and Reid et al. (1986). All correlations fit the data within two percent of error. While the air density correlation is very close to the ideal gas law, the heavy fuel vapor density is best described by (cf. McGlashan and Potter, 1962)

$$
\rho_{v}=\frac{p_{g}}{\kappa R_{v} T_{g}}
$$

where the compression factor

$$
\kappa=1-\left(\frac{B}{\forall_{c}}\right)\left(\frac{1}{\forall_{R}}\right)
$$

with

$$
\frac{B}{\forall_{c}}=0.430-\frac{0.884}{T_{R}}-\frac{0.694}{T_{R}^{2}}-\frac{0.0375(n-1)}{T_{R}^{4.5}}
$$

and $n$ is the number of carbon atoms in a fuel molecule. The reduced quantities are

$$
\forall_{R}=\frac{\forall}{\forall_{c}} \quad \text { and } \quad T_{R}=\frac{T}{T_{c}}
$$

Characteristic data for the fluids at different reference conditions are given in Table I. 
Table I.

Liquid and gas phase fluid properties at reference conditions.

\begin{tabular}{|c|c|c|c|c|c|c|c|}
\hline $\begin{aligned} p_{\infty} & =10 \mathrm{~atm} \\
T_{\infty} & =800 \mathrm{~K} \\
T_{0} & =300 \mathrm{~K}\end{aligned}$ & $\begin{array}{c}\rho \\
\left(\frac{3}{c^{3}}\right) \\
\end{array}$ & $\begin{array}{c}c_{p} \\
\left(\frac{c a l}{g K}\right) \\
\end{array}$ & $\begin{array}{c}h \\
\left(\frac{c a l}{c m \text {.aec. })^{k}}\right) \\
\end{array}$ & $\begin{array}{c}\mu \mathrm{g} \\
\left(\frac{\mathrm{g}}{\mathrm{cm} \cdot \mathrm{sec}}\right) \\
\end{array}$ & $\begin{array}{c}M_{v} \\
(--) \\
\end{array}$ & $\begin{array}{l}T_{b p} \\
(K) \\
\end{array}$ & $\begin{array}{c}\mathcal{D} \\
\left(\frac{\mathrm{cm}^{2}}{\mathrm{sec}}\right) \\
\end{array}$ \\
\hline n-hexane (liq.) & 0.6543 & 0.5360 & $2.946 \mathrm{E}-4$ & $2.911 \mathrm{E}-3$ & 86 & 438 & 0.0361 \\
\hline gas (at infinity) & $4.366 \mathrm{E}-3$ & 0.2621 & $1.389 \mathrm{E}-4$ & $3.694 \mathrm{E} 4$ & - & - & - \\
\hline $\begin{aligned} p_{o 0} & =10 \mathrm{~atm} \\
T_{\infty} & =1200 \mathrm{~K} \\
T_{0} & =350 \mathrm{~K}\end{aligned}$ & $\begin{array}{c}p \\
\left(\frac{a}{c m^{3}}\right) \\
\end{array}$ & $\begin{array}{c}c_{p} \\
\left(\frac{c a l}{g . h}\right) \\
\end{array}$ & $\begin{array}{c}k \\
\left.\frac{\cos }{\operatorname{cmsech} s^{2}}\right) \\
\end{array}$ & $\begin{array}{c}\mu \\
\left(\frac{2}{c m \cdot s e c}\right) \\
\end{array}$ & $\begin{array}{c}M_{v} \\
(-) \\
\end{array}$ & $\begin{array}{l}T_{b p} \\
(K) \\
\end{array}$ & $\begin{array}{c}\mathcal{D} \\
\left(\frac{\mathrm{cm} \mathrm{m}^{2}}{\mathrm{sec}}\right)\end{array}$ \\
\hline n-hexane (liq.) & 0.6058 & 0.5855 & $2.642 \mathrm{E}-4$ & $1.918 \mathrm{E}-3$ & 86 & 438 & 0.06903 \\
\hline gas (at infinity) & $2.911 \mathrm{E}-3$ & 0.2729 & $1.683 \mathrm{E}-4$ & $4.775 \mathrm{E}-4$ & -- & - & - \\
\hline
\end{tabular}

Averaged Interfacial Properties

In general. averaged surface properties, such as heat flux, vapor flux, shear stress, etc., are evaluated by integration of the local variable. viz

$$
\bar{g}=\frac{1}{2} \int_{0}^{\pi} g(\theta) \sin \theta d \theta
$$

Thus, the gas-phase. surface-averaged Nusselt number and Sherwood number based on freestream properties can be calculated as

$$
\overline{N u_{g}}=\frac{\bar{h} d^{*}(t)}{k}=\frac{2 a(\tau)}{\lambda_{g, \infty}\left(1-\bar{T}_{s}\right)}\left(\vec{q}_{h, g}^{\prime \prime} P e_{h, g}\right)
$$

and

$$
\bar{S} h_{g}=\frac{\bar{h} d^{*}(t)}{\rho D}=\frac{2 a(\tau)}{\omega_{g, \infty} Y_{s}^{\prime}}\left(\frac{\xi_{q, a}}{\xi_{g, \infty}}\right)\left(\vec{q}_{m, g}^{\prime \prime} P e_{m, g}\right)
$$

The total drag on each vaporizing interacting droplet is due to friction drag, pressure drag and, usually negiigible. thrust drag.

$$
c_{F}=-\cdots+\left.\frac{1}{2} \int_{0}^{\pi} T_{r \theta}\right|_{r=a(r)} \sin ^{2} \theta d \theta
$$




$$
\begin{gathered}
c_{P}=\left.2 \int_{0}^{\pi} p\right|_{r=a(\tau)} \sin 2 \theta d \theta \\
c_{T}=4 \int_{0}^{\pi}\left(u_{n}^{2} \cos \theta-2 u_{n} u_{t} \sin \theta\right) \sin \theta d \theta
\end{gathered}
$$

The total drag is occasionally plotted in form of the ratio $\alpha_{k}=C_{D}^{(k)} / C_{D s}$, where from Clift et al. $(1978)$

$$
C_{D_{1}}=\frac{24}{R e}\left(1+0.1935 R e^{0.6305}\right) \quad \text { for } 20<R e<260
$$

\section{NUMERICAL SOLUTIION}

The governing equations (1) - (7), subject to the conditions (9) - (17) are solved using a modified and extended finite-elernent software package (cf. Engelman, 1990 and Chiang, 1991). For this convective-dominated flow problem aine-node isoparametric quadrilateral elements are used (cf. Cuvelier et al., 1986). Bi-linear shape functions are selected for the pressure approximations while bi-quadratic shape functions are employed for the other field variables. Very small elements are placed and updated at the receding interface, where $\Delta \theta=3.2^{\circ}$. and large elements are located near the domain boundaries. A smooth transition from fine to coarse mesh regions has been achieved. For the multiple droplet systems, mesh renewal is not only necessary in the radial direction because of droplet shrinkings, but also in the axial direction following the relative motion of the second and third droplet with respect to the fixed frame at the center of the lead droplet. In order to maintain uniform mesh distributions for every time step, interpolations of the field variables (i.e., velocity, temperature and concentration) are made at the end of each time step so that computations can be continued with the new mesh. A very small time step is used (e.g., $\Delta \tau<2.5)$ for the multiple droplet system in order to minimize "false diffusion" caused by interpolations. The overall mesh size has been obtained in accordance with the boundary conditions by trial and error. Independence of the simulation results from the mesh density has been successfully tested based on repeat calculations with finer meshes.

The solution is started with the calculation of the gas-side interfacial shear stress, heat flux and mass flux in order to evaluate the liquid-phase velocity and temperature distri- 
butions. Matching of the interfacial boundary conditions has been obtained within six iterations, where $\epsilon=\left|\forall^{\text {new }}-\forall^{\text {oid }}\right|<10^{-4}$, using an under-relaxation coefficient of 0.6 to 0.7. All fluid properties are constantly updated with the new local temperatures and vapor concentrations. As mentioned in the preceding section, the two-phase regions are solved sequentially, because of their different convergence requirements and for reasons of computational efficiency. For example, since the liquid phase is subjected to Neumann-type boundary conditions, a more stable but slower iteration scheme, i.e., the successive substitution method, has been applied. Furthermore, instead of solving a very large system of combined gas-phase and liquid-phase equations, the segregated solution procedure requires less computer time. Each droplet is updated individually because of its unique scales of the salient transfer mechanisms. Necessary local mesh regeneration due to droplet shrinking and adjustment of the inlet free-stream (or droplet) velocity due to droplet deceleration, are performed at the end of each time step. An inertia term for equation (15b) as suggested by Chiang et al. (1989) was found to be insignificant in this study. The computational procedure has been terminated after about $50 \%$ of the droplet mass had been evaporated or imminent collision has been observed. A complete case run takes about 8 hours of CPU time for at single vaporizing droplet, and about 12 hours for the three-droplet system on a CRAY Y-MP. Future use of a conjugate-gradient based iterative solver will reduce run times of this large problem significantly.

\section{RESULTS AND DISCUSSION}

Within the limits of spherical droplets in laminar axisymmetric flow, the present computer simulation model could generate a seemingly unlimited number of data sets for fundamental and applied research analyses. Because of the restrictive supercomputer resources allocations, this base case study focuses on two representative initial spacings of three monodisperse, $n$ hexane fuel droplets at $R e_{s_{0}}=100, T_{o}^{*}=300 \mathrm{~K}$ or $350 \mathrm{~K}, T_{\infty}^{*}=800 \mathrm{~K}$ or $1200 \mathrm{~K}$ and $p_{\infty}^{*}=$ $10 \mathrm{~atm}$. 
In a continuous effort with respect to model validation (cf. Fig. 2), the numerical predictions for the drag coefficient ratio $\alpha_{1,2}$ vs. particle spacing $\left(d_{12}-1\right)$ are compared with the experimental data bands and (their besc-fitted) curves given by Rowe $\mathcal{d}$ Hendwood (1961). While the $\alpha_{1}\left(d_{12}-1\right)$ matching for the lead sphere happens to be very agreeable, the prediction of $\alpha_{2}\left(d_{12}-1\right)$ for the second sphere falls below the projected data curve, i.e., close to the lower bound of the experimental data spread. This may be due to interaction effects, such as a decrease in particle Reynolds number, not considered by Rowe \& Henwood (1961). Additional computer model validation tests have been successfully accomplished with experimental data sets for single-sphere, single-sphere with blowing, and two-sphere studies as documented in Ramachandran et al. (1989), Ramachandran et al. (1991) and Chiang and Kleinstreuer (1991a,b).

Case Study I: Initial Droplet Spacings $d_{12}=6$ and $d_{23}=6$; Initial $\Delta T^{*}=500 \mathrm{~K}$

This case study focuses on the transfer processes and dynamics of n-hexane droplets $\left(T_{0}^{*}=300 \mathrm{~K}\right)$ injected at $R e_{o}=100$ into heated air $\left(T_{\infty}^{*}=800 \mathrm{~K}, p_{\infty}^{*}=10 \mathrm{~atm}\right)$ at initially large spacings or low frequencies. As can be expected with $d_{23}=6$, the third droplet has only a minor impact on the second droplet which quickly catches up with the lead droplet.

The position, speed and size at all times of each interacting droplet are some of the more practical pararneters for spray design applications. The time and Reynolds number variations of the total drag coefficients, the surface-averaged gas-side Nusselt numbers and Sherwood numbers, as depicted in Figs. 3a,b to 5a,b, are instrumental in calculating these design parameters (cf. Figs. 5 to 8). The drag coefficient of the lead droplet, after a slight increase. drops rapidly when $\tau_{I} \geq 100$ due to the interaction, i.e., pairing effects between the second and the first droplet (cf. Fig. 3a). Correspondingly, the drag curve of droplet 2 decreases with time. The third droplet, much less affected by the preceding droplets, exhibits an almost constant total drag coefficient. The associated $C_{D}^{(k)}$-curves as a function of the instantaneous Reynolds number appear as mirror irnages in Fig. 3b. The single evaporating droplet correlation given by Renksizbulut \& Haywood (1988) overpredicts when compared with the drag of the leading droplet because of differences in interfacial conditions, such as 
the absence of a tangential velocity, and the existence of interaction effects which become transparent at $R e_{m} \leq 96$ for droplet 1 in this case. The heat transfer of the second droplet is largely determined by interaction effects as shown in Fig. 4a. For $\tau_{I} \geq 100$. when the se ond droplet is largely exposed to (fro-aft) recirculation zones, $\overline{N u}_{g, 2}$ drops even below $\overline{N u}_{g, 3}$. The heat transfer (cf. Fig. 4b) and mass transfer (cf. Fig. 5b) correlations given by Chiang (1991) and Chiang \& Kleinstreuer (1991c) match the leading droplet behavior rather well except during start-up. They were based on the experimental work of Renksizbulut \& Yuen (1983) with modifications significant for high-molecular-weight droplets such as $\mathrm{n}$-hexane fuel. As shown in Figs. 5a and 5b, the mass transfer is very similar for droplets 2 and 3 which are imbedded in the convective vapor stream generated by the lead droplet. As a result, the vaporization rates are similar for droplets 2 and 3 , while droplet 1 undergoes more drastic shrinkage (cf. Fig. 6). Figure 7 depicts the individual droplet speeds which are determined by the transient behavior of the parameters shown in Fig. 3 and Fig. 6.

Figure 8 compares the dynamics of interparticle spacings for three droplets (cf. Case D) with the dynamics of three spheres (cf. Cases A-C) of different initial separations and two (uniform) blowing intensities, i.e., $v_{b}=0$ and $v_{b}=0.1$. Case A, i.e., spheres without blowing, matches Case D, i.e., vaporizing droplets, rather well. In this scenario of weak surface blowing and interfacial slip (i.e., Case D), both transfer mechanisms tend to neutralize each other with respect to the total drag difference between two consecutive droplets. Specifically, relative motions between droplets/spheres are functions between the differences in individual drag coefficients which, in turn, are strongly dependent on the surface slip, blowing rate and inter-particle spacing. For example, surface blowing of the front droplet reduces the gas flow momentum around the trailing particles significantly; thus, reducing their drag coefficients which leads to a measurable increase in drag coefficient difference between the front and trailing particles (cf. Case B). In Case C, the second sphere, being in the wake of the lead sphere, catches up very quickly, leaving the third sphere isolated and hence permanently separated. 
Case Study II: Initial Droplet Spacings $d_{12}=6$ and $d_{23}=3 ;$ Initial $\Delta T^{*}=850 \mathrm{~K}$

In contrast to the previous scenario, Case Study II not only features a smaller initial spacing between the second and third droplet. but also a higher ambient temperature $\left(T_{\infty}^{*}=\right.$ $1200 \mathrm{~K})$ and a slightly higher initial droplet temperature $\left(T_{0}^{*}=350 \mathrm{~K}\right)$. These temperatures have a measurable impact on the fluid properties $\rho_{\infty}$ and $\mu_{\infty}$ and hence on the initial velocity of the lead droplet, i.e., $u_{0, I I}^{\mathrm{z}}=32 \mathrm{~m} / \mathrm{sec}$ in this case vs $u_{0, I}^{*}=17 \mathrm{~m} / \mathrm{sec}$ for the previous case. Hence, the dimensionless time scale $\tau=t u_{0}^{*} / d_{0}^{*}$ and the reference temperature $T_{\infty}^{*}$ change from Case Study I to Case Study II. In addition, the surface-averaged blowing velocity increased from $\bar{u}_{n, I} \approx 0.02 u_{o, I}$ to $\bar{u}_{n, I I} \approx 0.03 u_{\circ, I I}$.

Again, the integral quantities $C_{D}(\tau), \overline{N u}_{y}(\tau)$ and $\overline{S h}_{y}(\tau)$ shown in Figs. 9 to 11 largely determine the dynamic droplet parameters, such as size and speed which are depicted in Figs. 12 and 13. The trends in drag coefficients (cf. Figs. 3a,b and 9a,b) are rather similar between Case Study I and Case Study II which implies that the upstream effect of the third droplet on $C_{D}^{1,2}$ is weak for $0 \leq \tau \leq 80$. However, the magnitude of $C_{D}^{(k)}$ is lower because of enhanced surface slip which delays flow separation and stronger surface blowing which may reduce the total drag coefficient. The Renksizbulut \& Haywood correlation captures the $C_{D}\left(R e_{m}\right)$ trend except for $R e_{m} \leq 104$ or $\tau_{I I} \geq 120$, when interaction effects become significant (cf. Figs. 9a,b).

As can be expected, the transient Nusselt number distributions differ measurably between these two case studies because of the effects of higher temperatures, $T_{\infty}^{*}$ and $T_{0}^{*}$, and closer initial spacing, $d_{23}^{*}$. The stronger surface blowing increases the thermal boundary layer and decreases the normal temperature gradient which in turn results in lower Nusselt numbers, reflecting diminished convection effects (Fig. 10a). The Nusselt number of the third droplet is especially affected because of the prevailing influence of droplet 2 . In contrast to Case Study I, the Chiang \& Kleinstreuer correlation underpredicts here $N u_{g}\left(R e_{m}\right)$ in magnitude, but it is correct in predicting the trend for the leading droplet (cf. Fig. 10b). Adjustments in the definition of reference properties could optimize the overall curve agreements. Similar to heat transfer, mass transfer mechanisms are strongly determined by the initial temperatures and the relatively close distance between droplets 2 and 3 (cf. Fig. $11 \mathrm{a}$ ). 
Figure $11 \mathrm{~b}$ shows again the mirror image of the $S h_{g}\left(\tau_{I I}\right)$-curves with an acceptable fit of the $\mathrm{C}-\mathrm{K}$ correlation.

All three droplets experience a substantial reduction in liquid mass as a result of relatively strong blowing, until imminent droplet collision (cf. Fig. 12). Correspondingly, the instantaneous droplet Reynolds numbers (or travel speeds) decrease with time due to droplet shrinkage and deceleration (cf. Fig. 13).

Similar to Fig. 8, Fig. 14 depicts a comparable (dynamic) behavior between vaporizing droplets and solid spheres (cf. Case A vs. Cas $:$ ). For this particular set of initial conditions, sphere/droplet 3 approaches the second particle and both catch up with the lead particle, indicating imminent collision at $\tau_{I I} \approx 160$.

\section{CONCLUSIONS}

A study of the dynamics and transfer processes of three droplets which are injected into a high-temperature, stagnant-air environment has been presented. Variable fluid properties are assumed for the calculations of the gas phase and the liquid phase of this interacting vaporizing fuel droplet system. Suitable droplet initial temperatures $\left(T_{0}^{*}=300 \mathrm{~K}\right.$ or $\left.350 \mathrm{~K}\right)$, ambient conditions $\left(T_{\infty}^{*}=800 \mathrm{~K}\right.$ or $\left.1200 \mathrm{~K}, p_{\infty}^{*}=10 \mathrm{~atm}\right)$ and an initial droplet Reynolds number of $R e_{0}=100$ are chosen to simulate vaporization of $n$-hexane droplets on a onedimensional trajectory. For the dynamically interacting vaporizing droplet study, two initial droplet spacings, i.e., $d_{12}=6 ; d_{23}=6$ and $d_{12}=6 ; d_{23}=3$, are examined. The significance of this and complementary investigations is as follows:

(i) The relative motion between the liquid droplets in a dense spray system is mainly dependent on the surface blowing and surface slip velocity. Surface blowing increases the drag coefficient difference between successive droplets and causes a rapid approach of the droplets. Slip velocity, on the other hand, reduces the drag coefficient difference and results in the delay of droplet collision. 
(ii) The lead droplet and the second droplet have the strongest interaction effects. However, at a critical initial spacing (i.e., $d_{23} \leq 3$ ) and for initial Reynolds number of $\mathcal{O}(100)$, droplet collision between the second and third droplet is quite possible. On the other hand, even relatively large initial spacings such as $d_{12}=d_{23}=6$, the first two droplets tend to form a pair, whereas the third particle experiences permanent separation.

(iii) High droplet initial temperature and high ambient temperature reduce the transient, internal droplet heating period and generate large, rapid surface blowing effects. The injected vapor is convected downstream and changes the heat transfer and mass transfer of the downstream droplets significantly.

(iv) Existing correlations capture the dynamics, heat and mass transfer of the leading droplet rather well.

(v) For future work, additional case studies could generate a data base from which time history correlations of spray parameters, such as droplet size, speed and spacing, can be calculated.

\section{ACKNOWLEDGEMENTS}

This work has been supported in part by the Department of Energy, Office of Basic Energy Science, Grant No. DE-FG05-87ER13728. The support of the North Carolina Supercomputing Center (NCSC) under an Advanced Computing Resources Grant from the State of North Carolina is greatly appreciated. The assistance of Mr. James K. Comer in redrawing Figs. 3a-5b and Figs. 9a-11b is gratefully acknowledged. 


\section{REFERENCES}

Chiang, H. and Kleinstreuer, C. (1991a). Laminar flow past colinear spheres with fluid injection, $A S M E$ J. Fluids Eng., 113 (2), 176-182.

Chiang, H. and Kleinstreuer, C. (1991b). Convection heat transfer of co-linear interacting droplets with surface mass transfer, Int. J. Heat Ef Fluid Flow, 12, (3), 240-248.

Chiang, H. and Kleinstreuer, C. (1991c). Numerical analysis of variable-fluid-property effects on the convective heat and mass transfer of high-molecular-weight droplets.

(under review).

Chiang, H. (1991). Numerical analysis of interacting spheres and vaporizing droplets. Ph.D. thesis, MAE Dept., NCSU, Raleigh, NC.

Chiang, C. H., Raju, M. S. and Sirignano, W. A. (1989). Numerical analysis of convecting, vaporizing fuel droplet with variable properties, 27th Aerospace Sciences Meeting, Reno, Nevada; Paper \#AIAA-89-0834.

Clift, R., Grace, J. R. and Weber, M. E. (1978). Bubbles, Drops and Particles, Academic Press, New York).

Cuvelier, C., Segal, A. and Van Steenhoven, A. A. (1986). Finite Element Methods and NavierStokes Equations, D. Reidel Publishing Company, Dordrecht, Holland.

Dwyer, H. A. (1989). Calculations of droplet dynamics in high temperature environments, Prog. Energy Combust. Sci., 15, 131-158.

Engelman, M. (1990). FIDAP Manuals, Version 5.0, FDI, Evanston, IL.

Faeth, G. M. (1987). Mixing, Transport and combustion in sprays, Prog. Energy Comb. Sci., $13,293-345$.

Haywood, R. J., Nafziger, R. and Renksizbulut, M. (1989). A detail examination of gas and liquid phase transient processes in convective droplet evaporation, $J$. of Heat Transfer, 111, 495-502.

Kleinstreuer, C. and Wang, T.-Y. (1990). Approximate analysis of interacting vaporizing fuel droplets, Int. J. Multiphase Flow, 16 (2), 295-304.

Kuo, C. K. (1986). Principles of Combustion, Wiley-Interscience, New York, N.Y..

Law, C. K. (1984). Heat and mass transfer in combustion: fundamental concepts and analytical techniques, Prog. Energy Comb. Sci., 10, 295-318.

Law, C. K. (1990). Consideration in droplet processes in liquid hazardous waste incineration, Combust. Sci. and Tech., 74, 1-15.

McGlashan, M. L. and Potter, D. J. B. (1962). An apparatus for the measurement of the second 
vivial coefficients of vapours; the second vivial coefficients of some $\mathrm{n}$-alkames and of some mixtures of n-alkanes, Proceedings Royal Society of London (a), 267, 478-500.

Mulholland, J. A., Srivastava, R. K. and Wendt, J. O. L. (1988). Influence of droplet spacing on drag coefficient in nonevaporating monodisperse streams, AIAA Journal, 26, No. 10, 1231-1237.

Raju, M. S. and Sirignano, W. A. (1987). Unsteady Navier-Stokes solution for two interacting vaporizing droplets, AIAA 25th Aerospace Science Mtg., Jan. 12-15, Reno, Nevada. Or: Physics of Fluids A 2 (10), 1780-1796 (Oct 1990).

Ramachandran. R. S., Kleinstreuer, C., and Wang, T-Y (1989). Forced convection heat transfer of interacting spheres, Num. Heat Transfer, Part A, 15, 471-487.

Ramachandran. R. S., Wang, T-Y, Kleinstreuer, C. and Chiang, H. (1991). Laminar flow past three closely-spaced monodisperse spheres or nonevaporating drops, AIAA Journal. 29, (1), 43-56.

Reid, R. C., Pransnitz, J. M. and Poling, B. E. (1986). The properties of gases and liquids, 4th, McGraw-Hill Co., New York, NY.

Renksizbulut, M. and Yuen, M. C. (1983). Experimental study of droplet evaporation in a high-temperature air stream, ASME J. of Heat Transfer 105, 384-388.

Renksizbulut, M. and Haywood, R. J. (1988). Transient droplet evaporation with variable properties and internal circulation at intermediate Reynolds numbers, Int. J. Multiphase Flow, $14(2), 189-202$.

Rowe, P. N. and Henwood, G. A. (1961). Drag forces in a hydraulic model of a fluidized bed Part I, Trans. Inst. Chem. Engr., 39, 43-56.

Sirignano, W. H. (1983), Fuel droplet vaporization and spray combustion theory, Prog. Energy Combust. Sci., 9, 291-322.

Tsuji, Y., Morikawa, Y., and Terashima, K. (1982). Fluid-dynamic interaction between two spheres, Int. J. Multiphase Flow, 8, 71-82.

Vargaftik, N. B. (1975). Tables on the Thermophysical properties of Liquids and Gases, 2nd, Hemisphere Publishing Co., Washington, D.C.

Wilke, A. (1950). A Viscosity Equation for Gas Mixtures, J. Chemical Physics, 18, (4), 517-519.

Yaw, C. L. (1977). Physical Properties, McGraw-Hill, New York, NY. 


\section{LIST OF FIGURES}

Fig. 1

Fig. 2

Fig. 3a

Fig. 3b

Fig. $4 \mathrm{a}$

Fig. 4b

Fig. 5a

Fig. 5b

Fig. 6

Fig. 7

Fig. 8

Fig. 9a

Fig. 9b

Fig. 10a
System schematics for vaporizing interacting droplets on a onedimensional trajectory.

Comparison between predicted and measured drag coefficient ratio for two interacting spheres.

Droplet drag coefficients vs. time $\left(R e_{d_{0}}=100, T_{o}=300 \mathrm{~K}, T_{\infty}=800 \mathrm{~K}\right.$, $p_{\infty}=10$ atm; $\left.\left.d_{12}\right|_{0}=\left.d_{23}\right|_{0}=6\right)$.

Droplet drag coefficients vs. instantaneous Reynolds number and comparison with Renksizbulut-Haywood correlation.

Droplet Nusselt numbers vs. time $\left(R e_{d_{0}}=100, T_{0}=300 \mathrm{~K}, T_{\infty}=\right.$ $\left.800 K, p_{\infty}=10 \mathrm{~atm} ;\left.d_{12}\right|_{0}=\left.d_{23}\right|_{0}=6\right)$.

Droplet Nusselt numbe " vs. instantaneous Reynolds number and comparison with Chiang- $K$ instreuer correlation.

Droplet Sherwood numbers vs. time $\left(R e_{d_{0}}=100, T_{o}=300 \mathrm{~K}, T_{\infty}=\right.$ $\left.800 \mathrm{~K}, p_{\infty}=10 \mathrm{~atm} ;\left.d_{12}\right|_{0}=\left.d_{23}\right|_{0}=6\right)$.

Droplet Sherwood numbers vs. instantaneous Reynolds number and comparison with Chiang-Kleinstreuer correlation.

Droplet radii vs. time $\left(R e_{d o}=100, T_{0}=300 \mathrm{~K}, T_{\infty}=800 \mathrm{~K}, p_{\infty}=10\right.$ atm; $\left.\left.d_{12}\right|_{0}=\left.d_{23}\right|_{0}=6\right)$.

Droplet velocities vs. time $\left(R e_{d o}=100, T_{o}=300 \mathrm{~K}, T_{\infty}=800 \mathrm{~K}, p_{\infty}=\right.$ $\left.10 \mathrm{~atm} ;\left.d_{12}\right|_{0}=\left.d_{23}\right|_{0}=6\right)$.

Comparison between three dynamically interacting vaporizing droplets and three spheres (Cases A-D).

Droplet drag coefficients vs. time $\left(R e_{d_{0}}=100, T_{0}=350 \mathrm{~K}, T_{\infty}=\right.$ $1200 K, p_{\infty}=10$ atm; $\left.\left.d_{12}\right|_{0}=6,\left.d_{23}\right|_{0}=3\right)$.

Droplet drag coefficients vs. instantaneous Reynolds number and comparison with Renksizbulut-Haywood correlation.

Droplet Nusselt numbers vs. time $\left(R e_{d o}=100, T_{0}=350 \mathrm{~K}, T_{\infty}=\right.$ $\left.1200 K, p_{\infty}=10 \mathrm{~atm} ;\left.d_{12}\right|_{\mathrm{o}}=6,\left.d_{33}\right|_{\mathrm{o}}=3\right)$. 
Fig. 10b

Droplet Nusseit numbers vs. instantaneous Reynolds number and comparison with Chiang-Kleinstreuer correlation.

Fig. 11a Droplet Sherwood numbers vs. time $\left(R e_{d o}=100, T_{o}=350 \mathrm{~K} . T_{\infty}=\right.$ $1200 K, p_{\infty}=10$ atm; $\left.\left.d_{12}\right|_{0}=6,\left.d_{23}\right|_{0}=3\right)$.

Fig. 11b Droplet Sherwood numbers vs. instantaneous Reynolds number and comparison with Chiang-Kleinstreuer correlation.

Fig. 12 Droplet radii vs. time $\left(R e_{d_{o}}=100, T_{o}=350 \mathrm{~K}, T_{\infty}=1200 \mathrm{~K}, p_{\infty}=10\right.$ atm; $\left.\left.d_{12}\right|_{0}=6 .\left.d_{23}\right|_{0}=3\right)$.

Fig. 13

Droplet velocities vs. time $\left(R e_{d o}=100, T_{o}=350 \mathrm{~K}, T_{\infty}^{\prime}=1200 \mathrm{~K}, p_{\infty}\right.$ $\left.=10 \mathrm{~atm} ;\left.d_{12}\right|_{0}=6,\left.d_{23}\right|_{0}=3\right)$.

Fig. 14

Comparison between three dynamically interacting vaporizing droplets and three spheres (Cases A-C). 


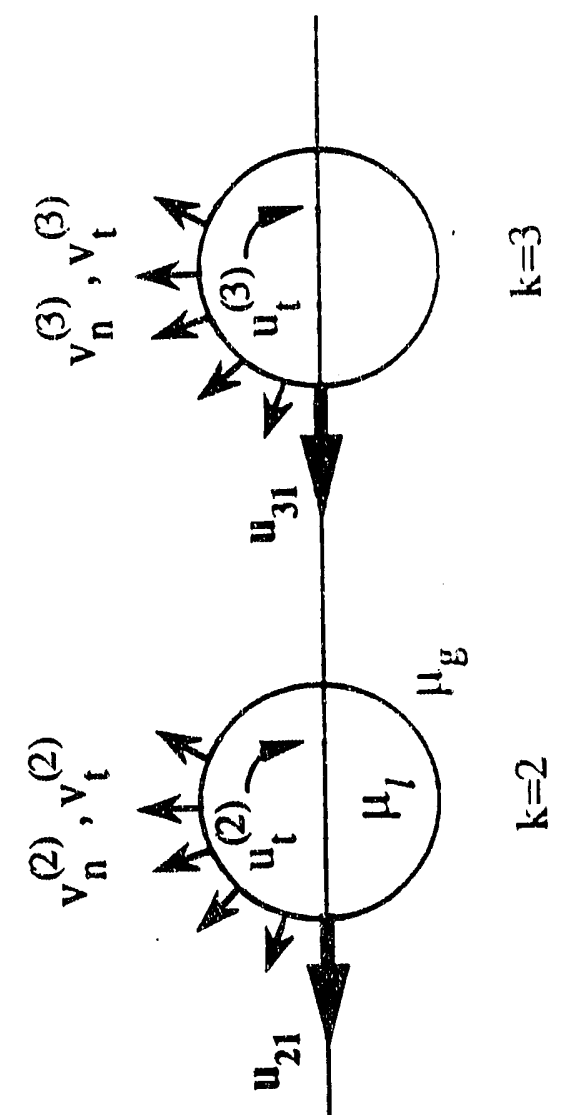

$i>^{\infty} e^{-\infty}>-\infty$
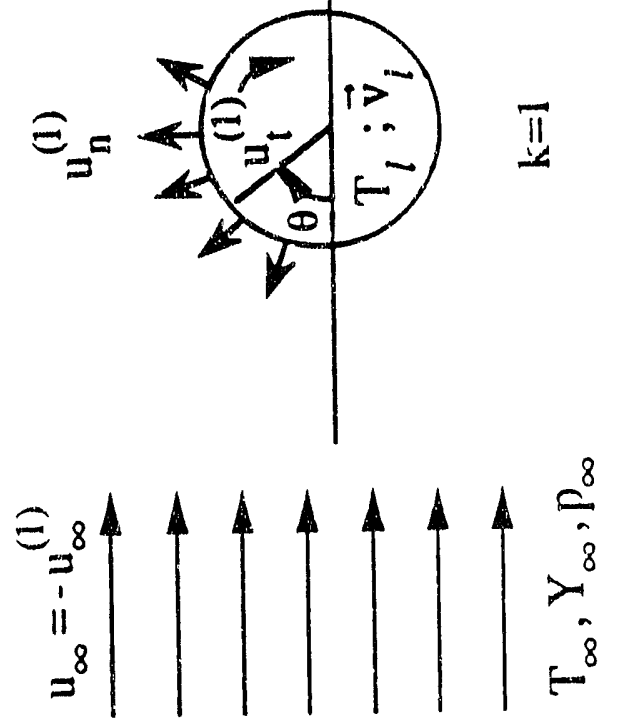


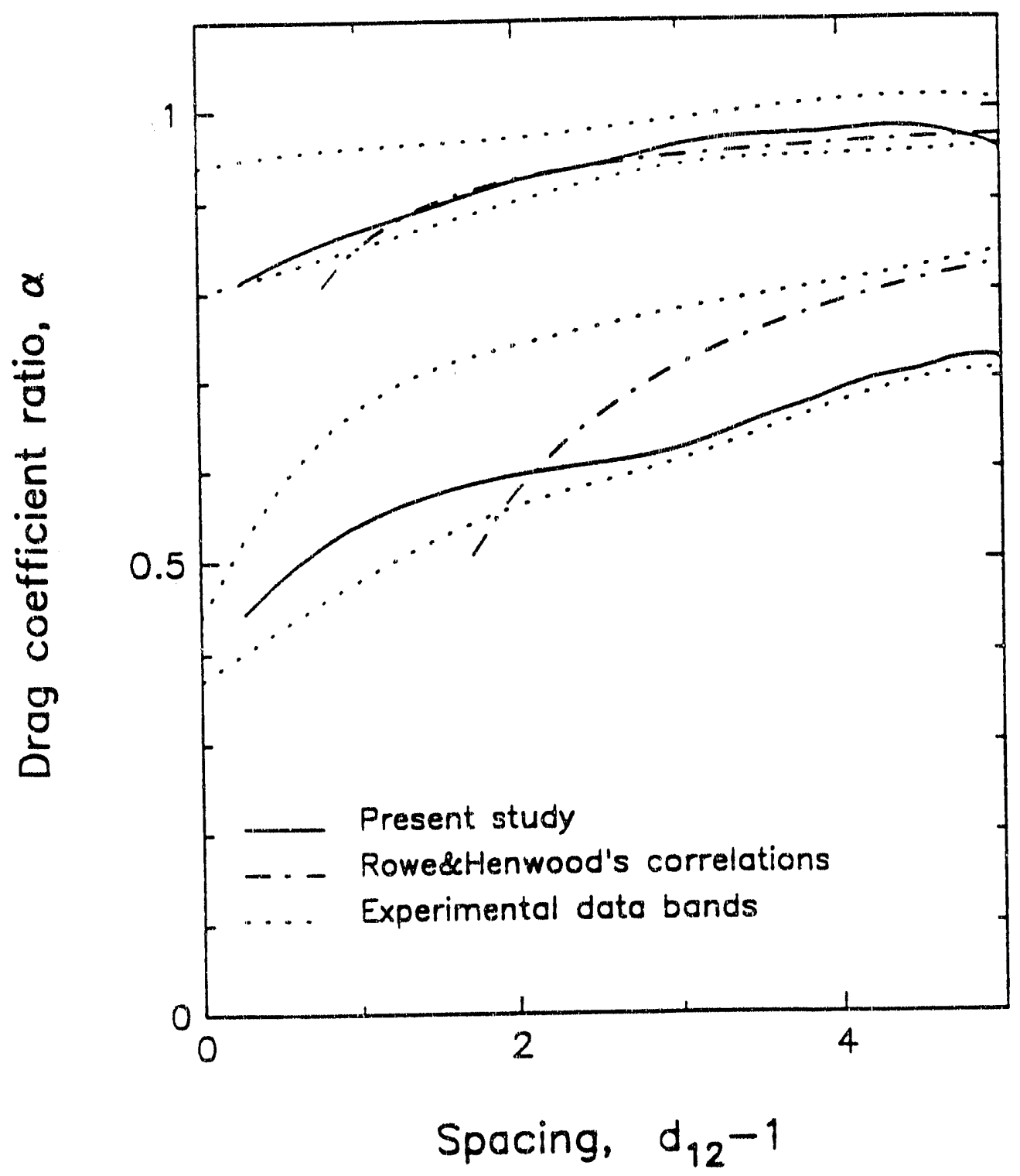



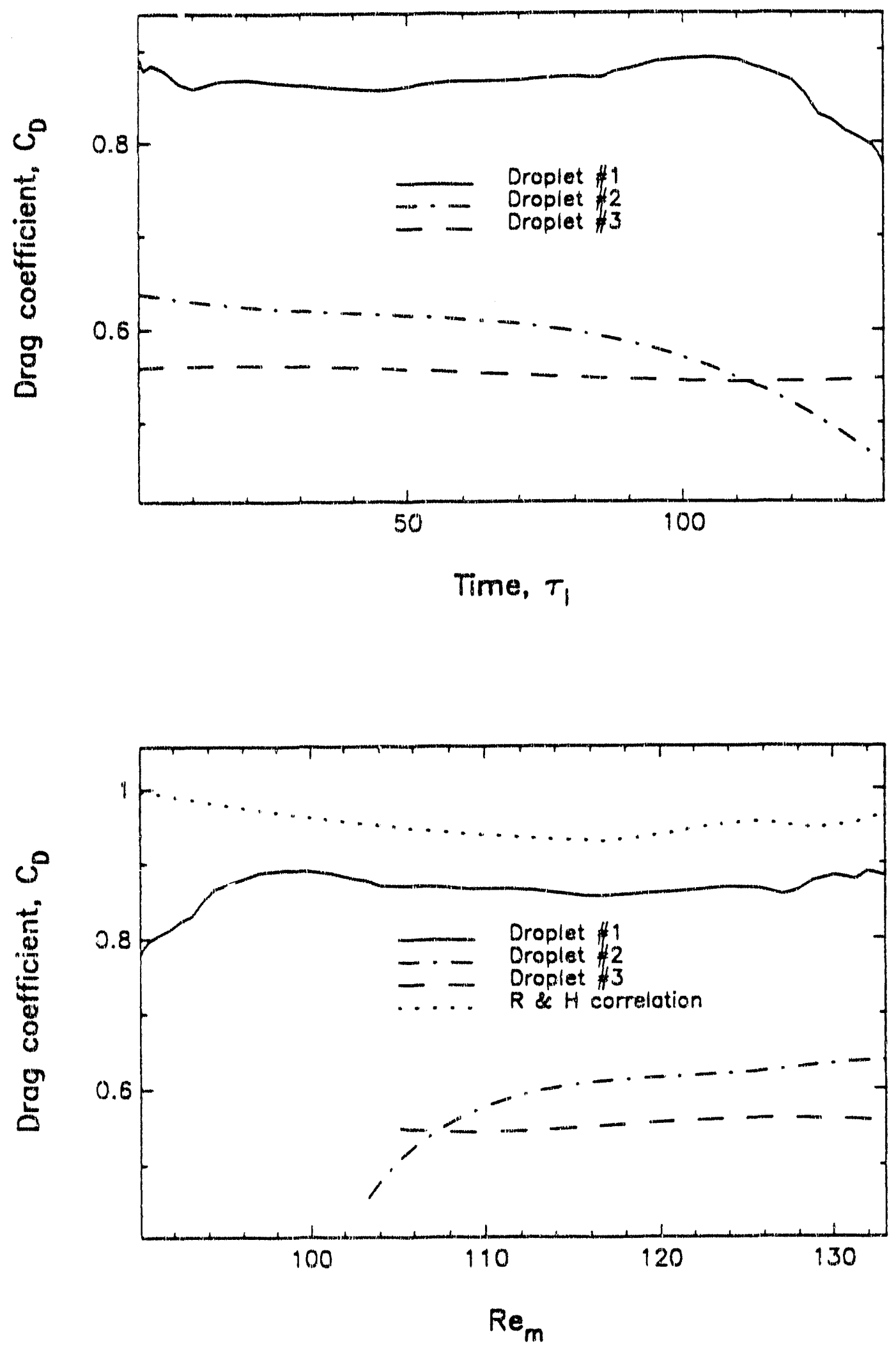


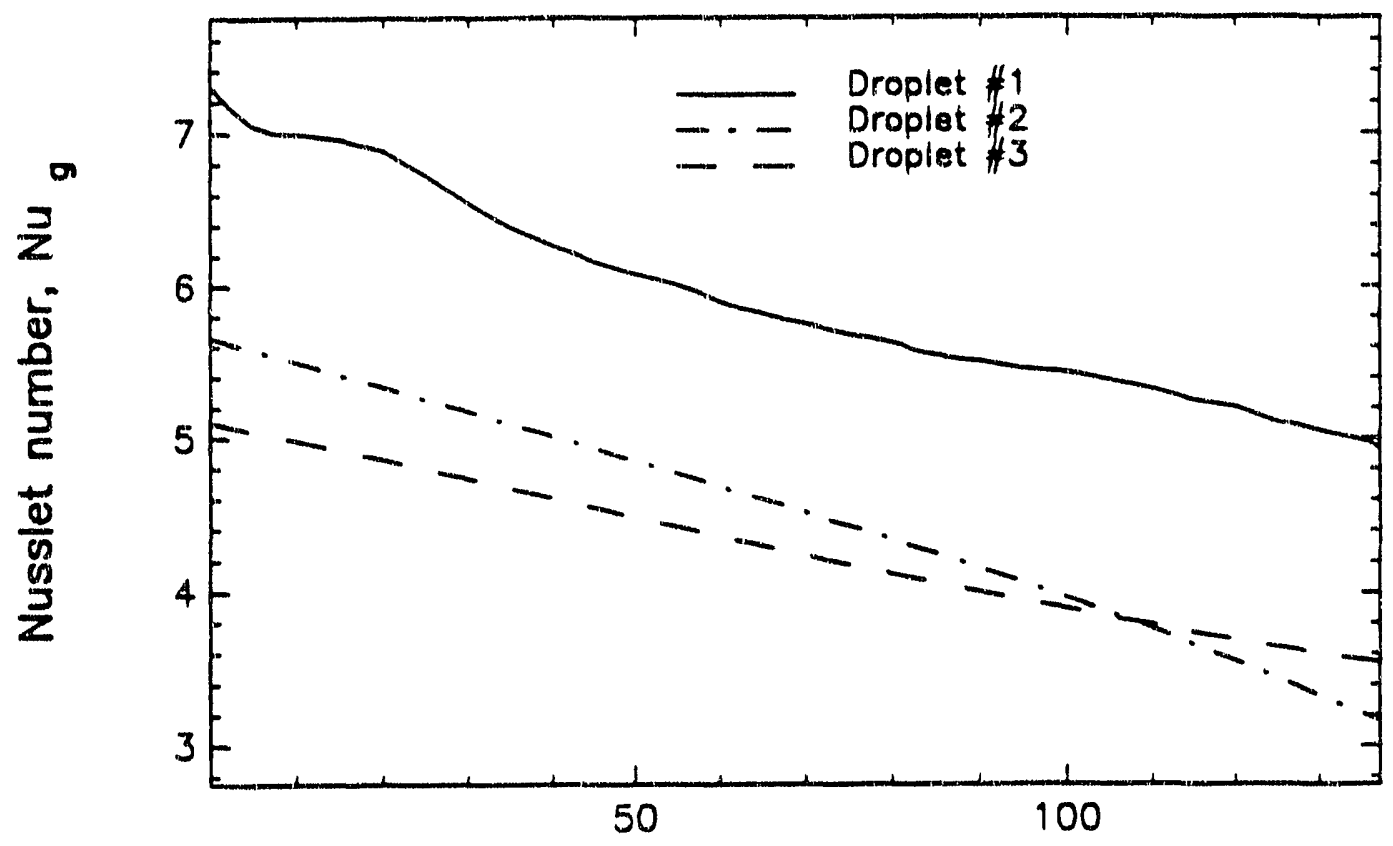

Time, $\boldsymbol{T}_{1}$

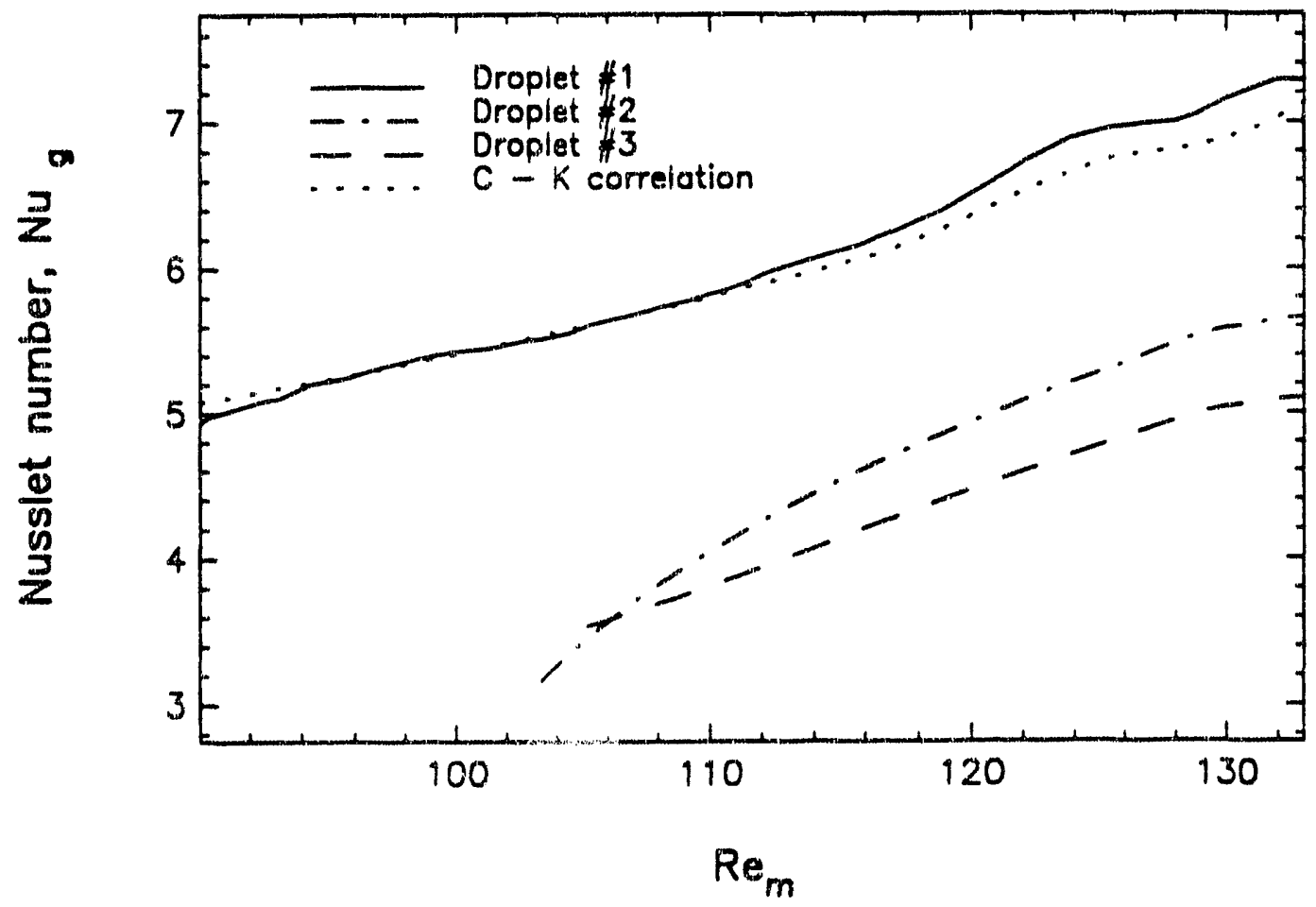




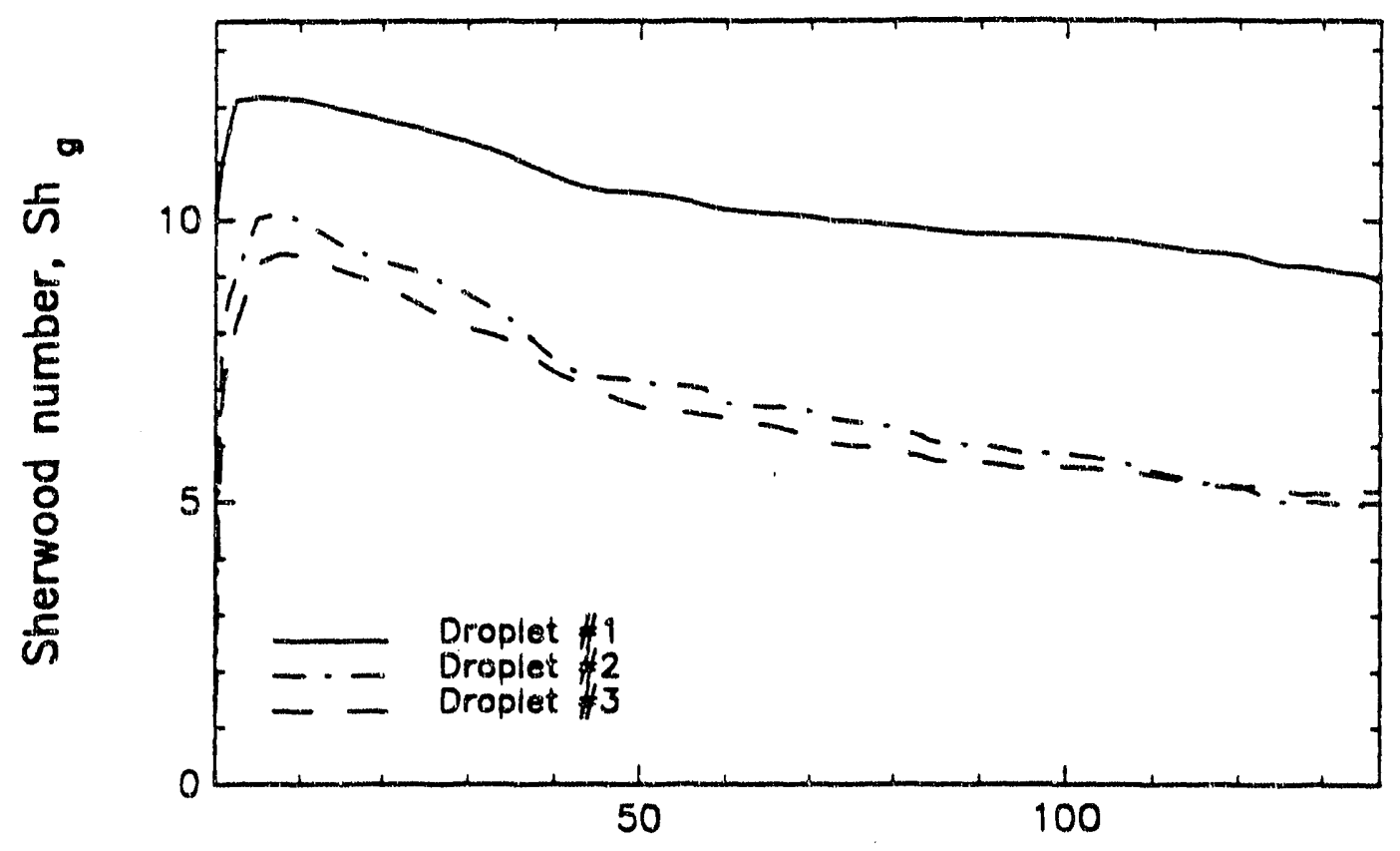

Time, $\tau_{1}$

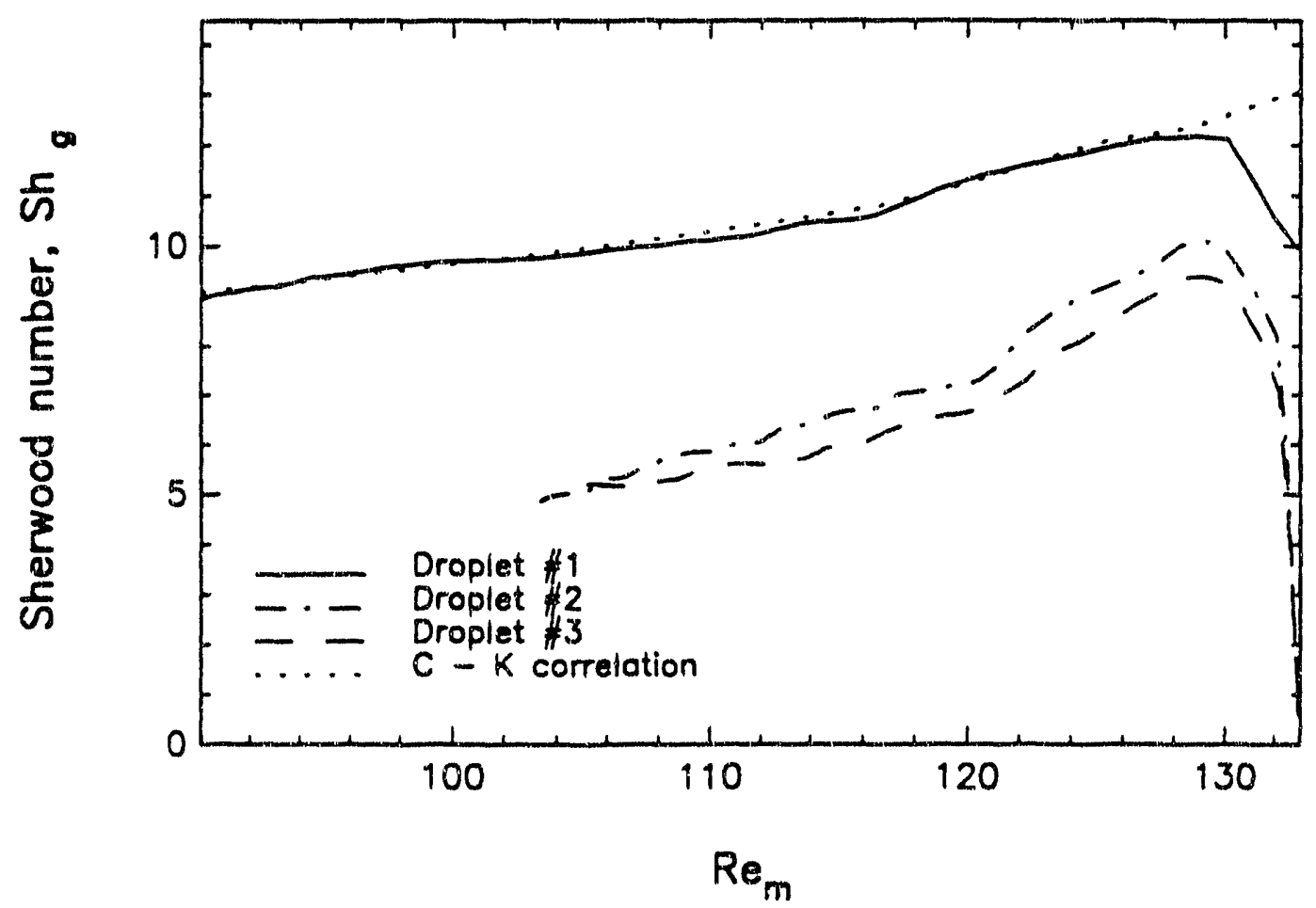




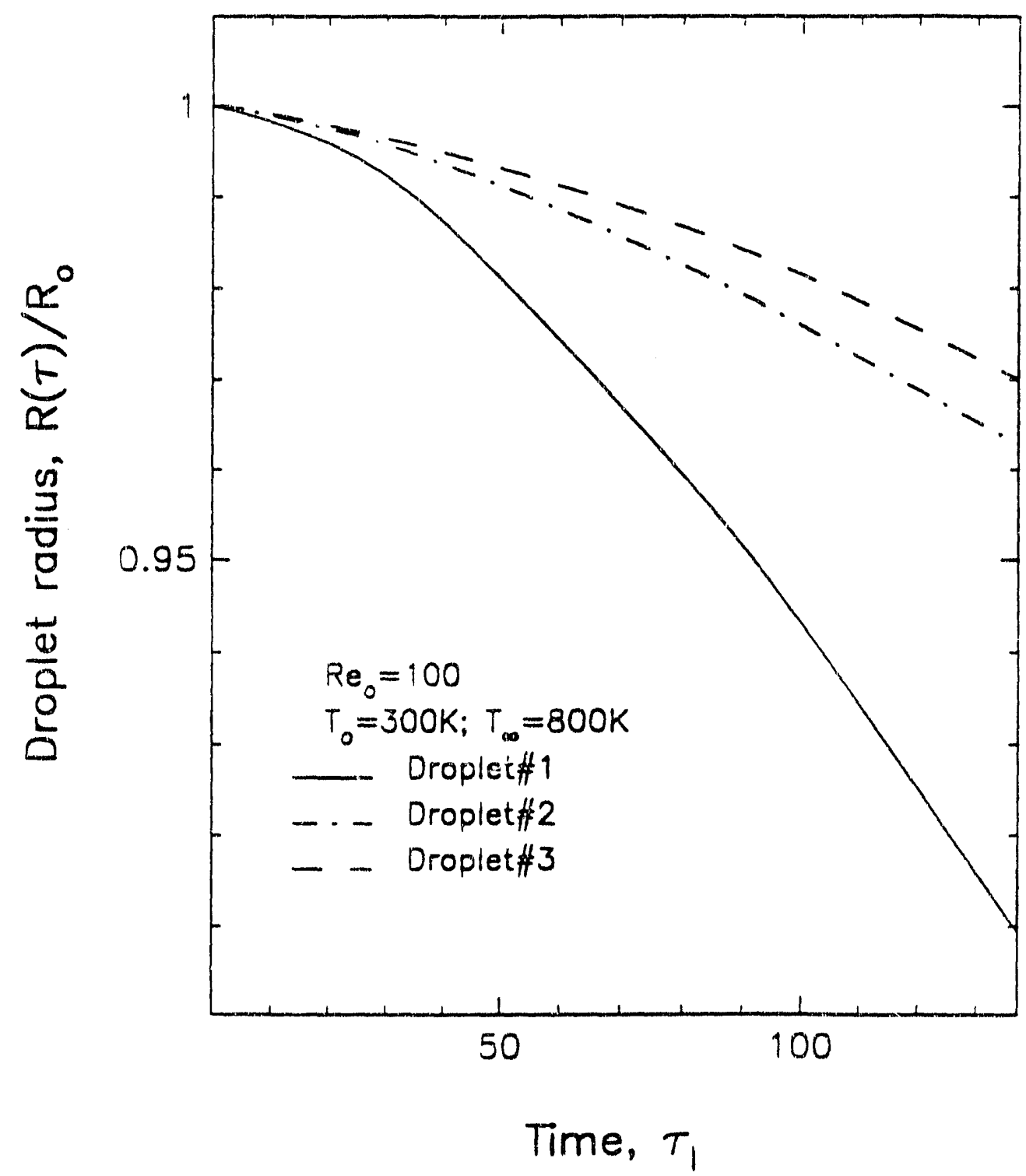




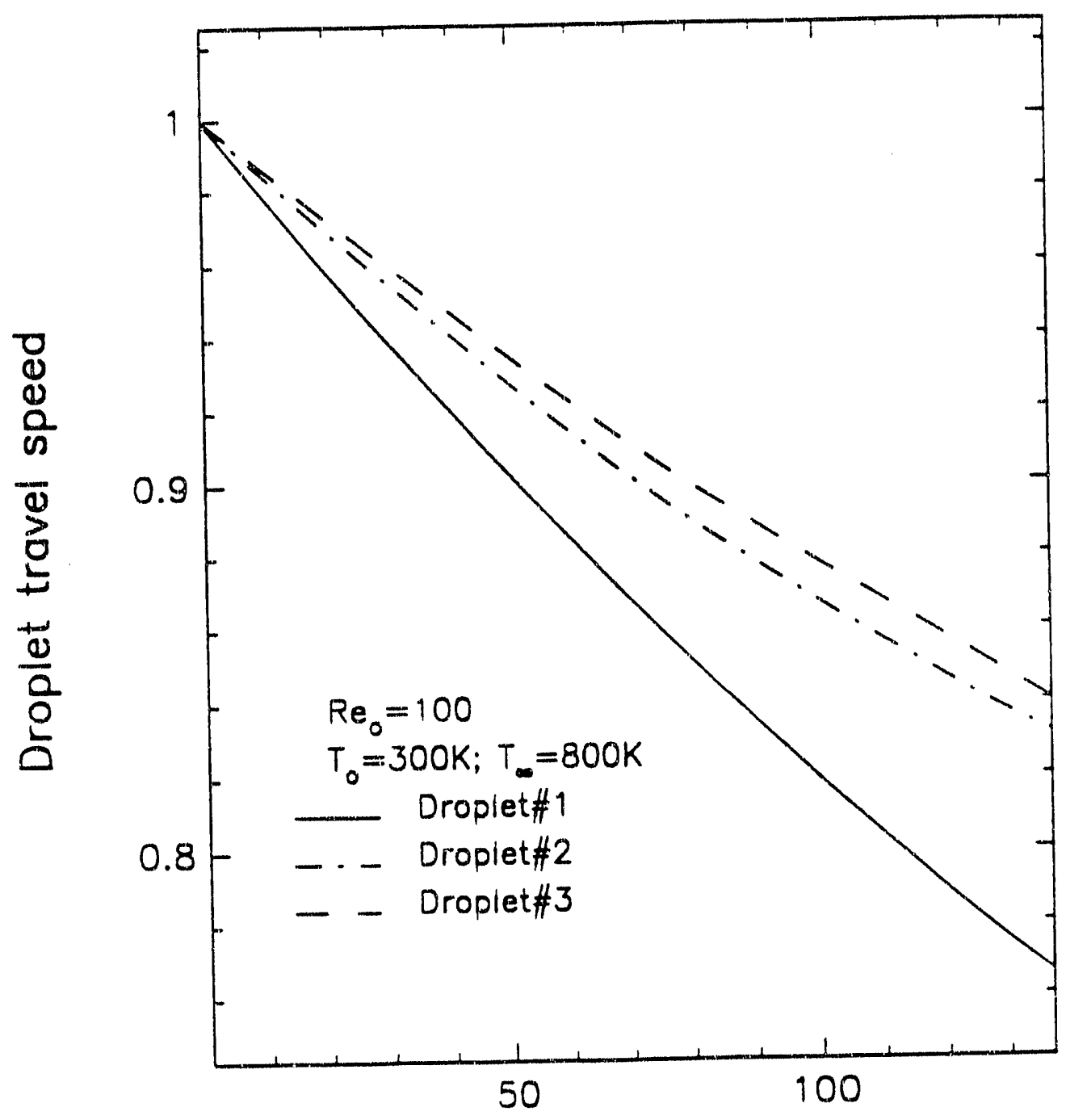

Time, $\tau_{1}$ 
cose $d_{i j}(\tau=0)$

$$
\begin{array}{llll}
\text { A } & d_{12}=6 & d_{23}=6 & v_{b}=0 \\
\text { B } & d_{12}=6 & d_{23}=6 & v_{b}=0.1 \\
\text { C } & d_{12}=3 & d_{23}=6 & v_{b}=0 \\
\text { D } & d_{12}=6 & d_{23}=6 & \text { droplets }
\end{array}
$$

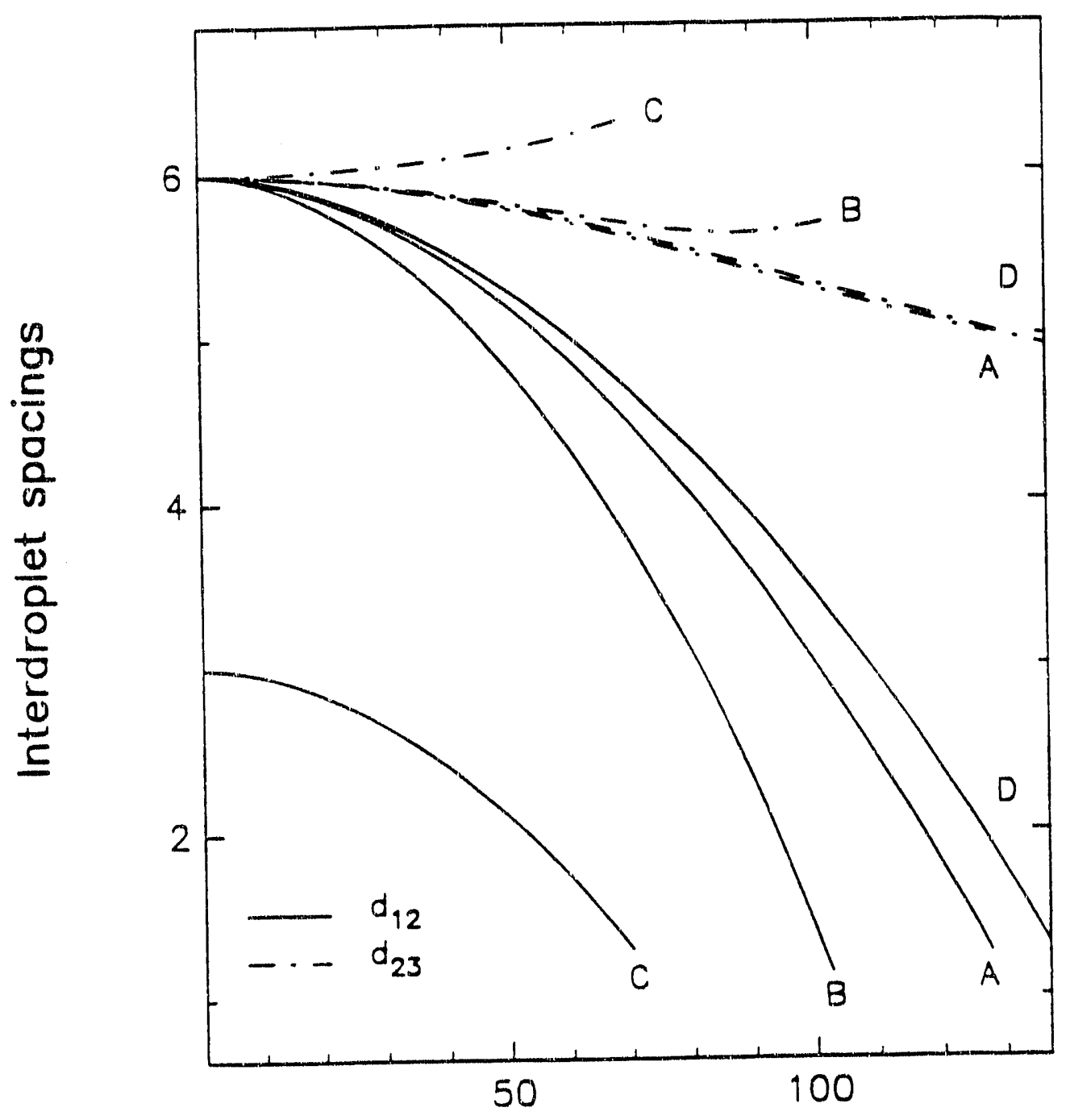

Time, $\tau_{1}$ 


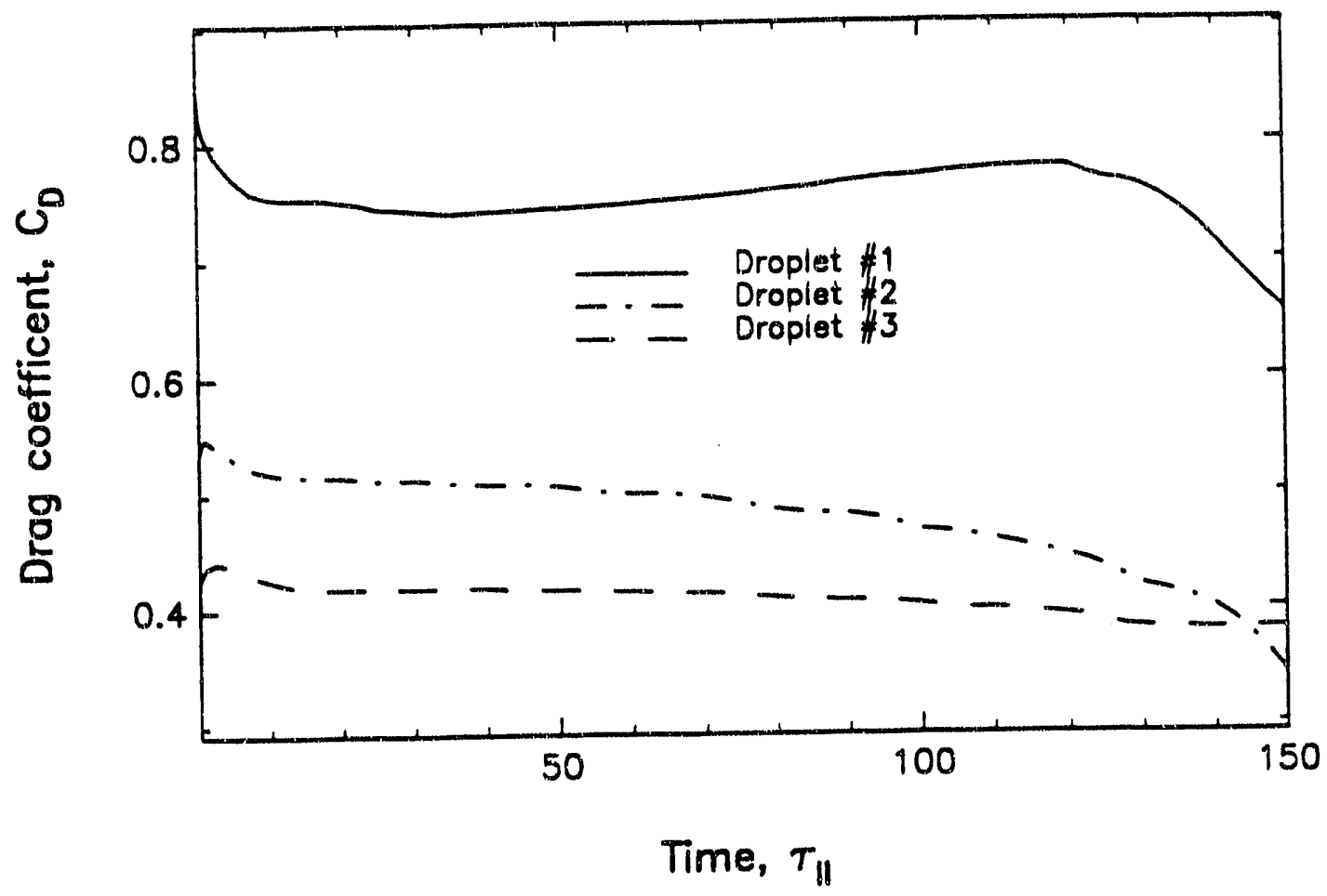

$a$

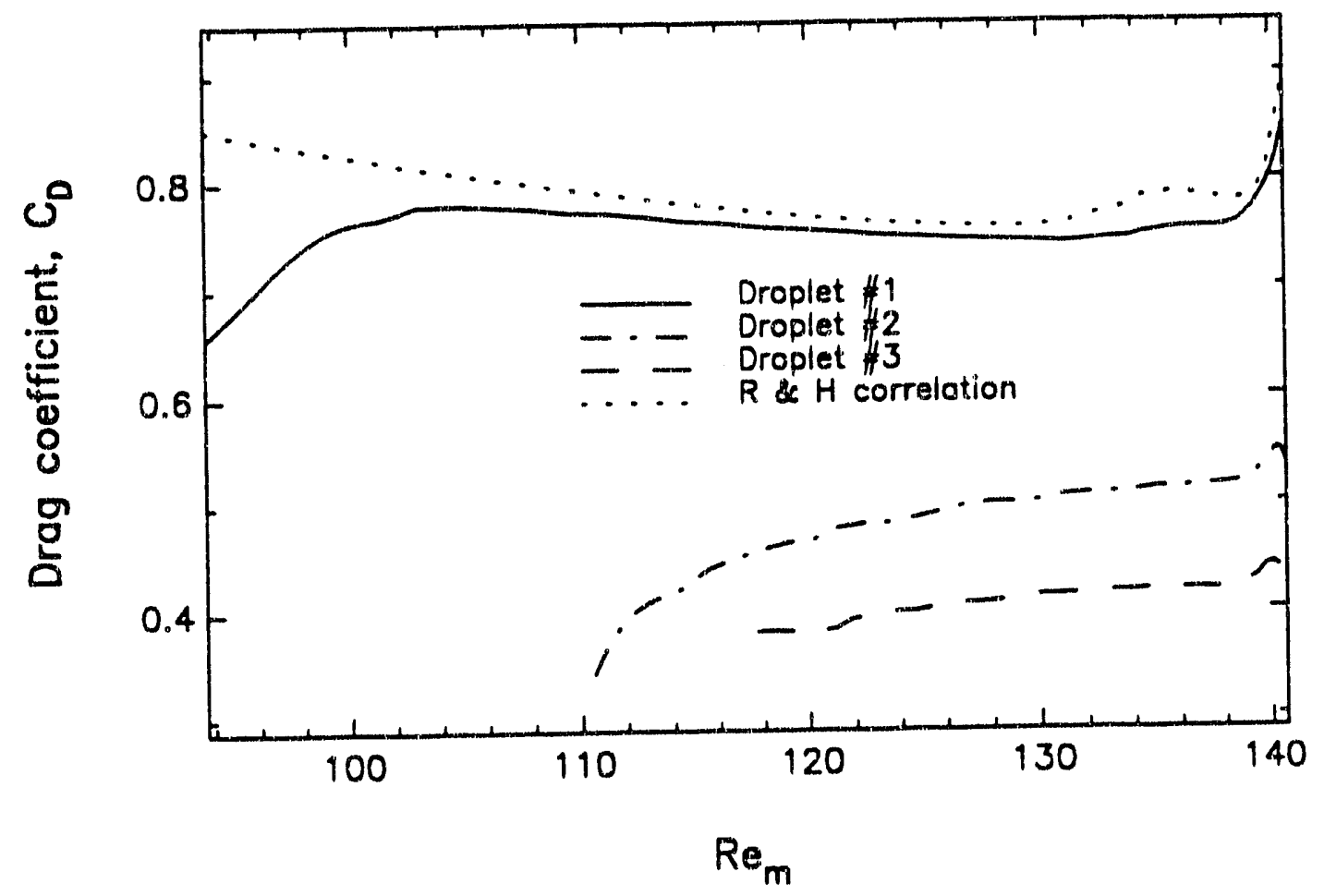




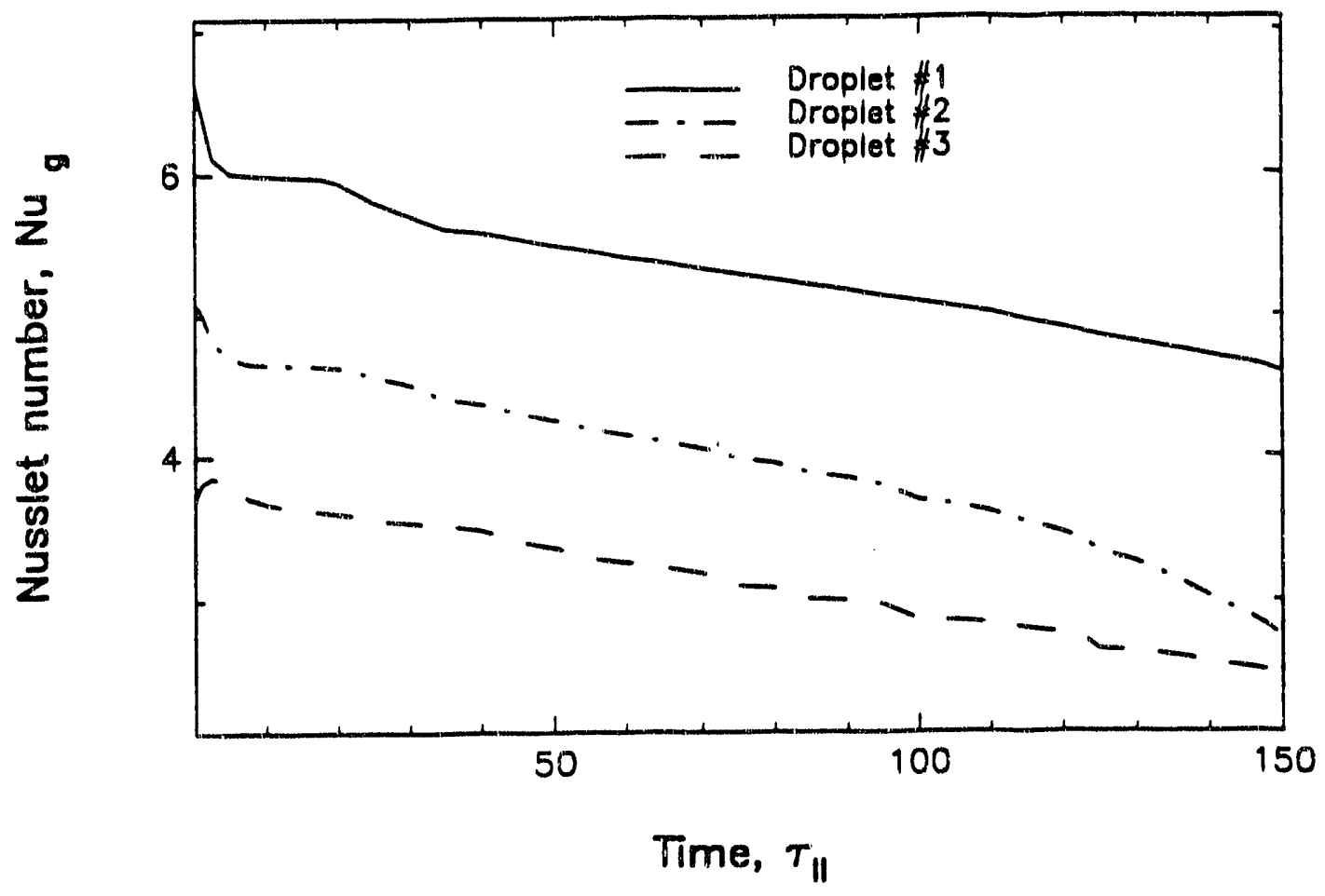

$a$

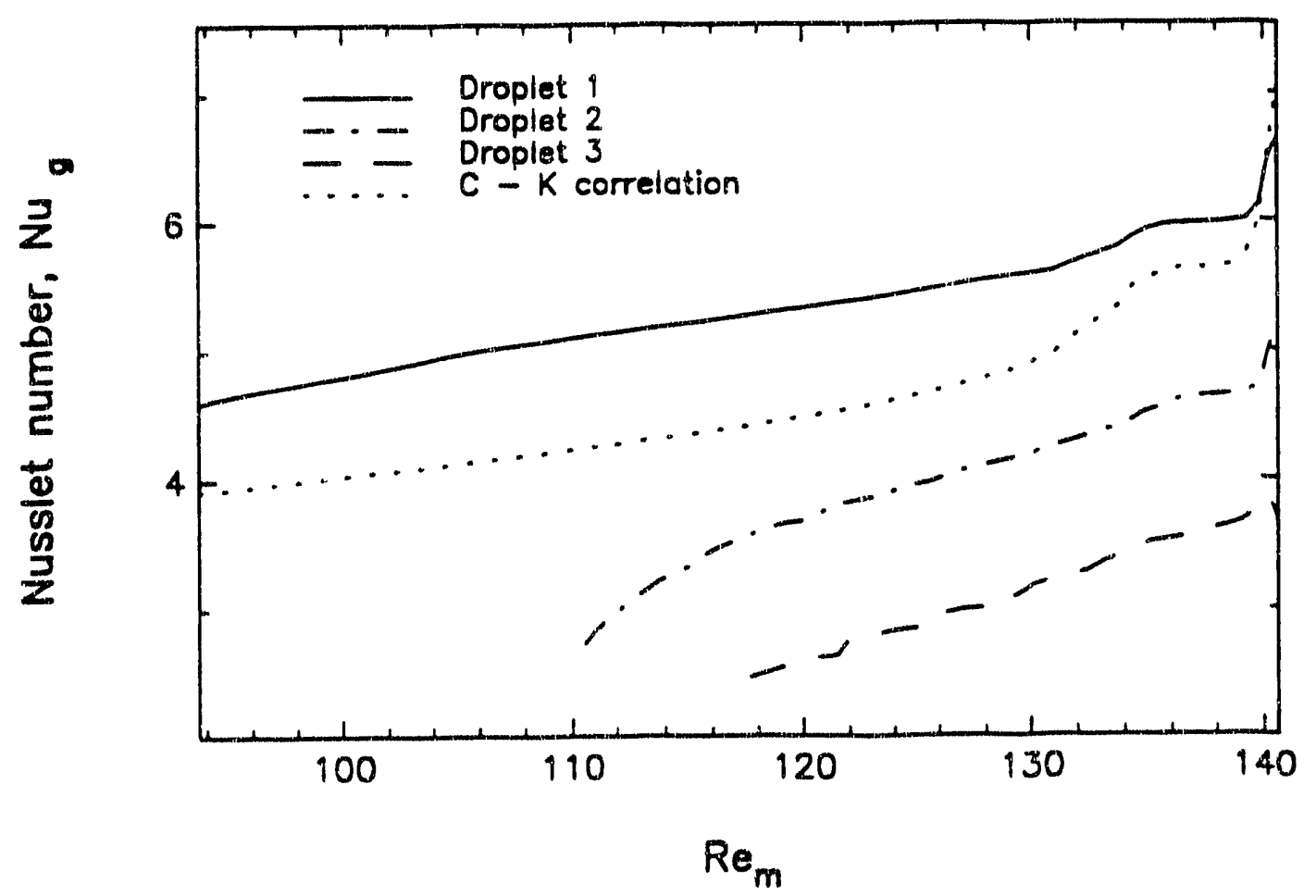



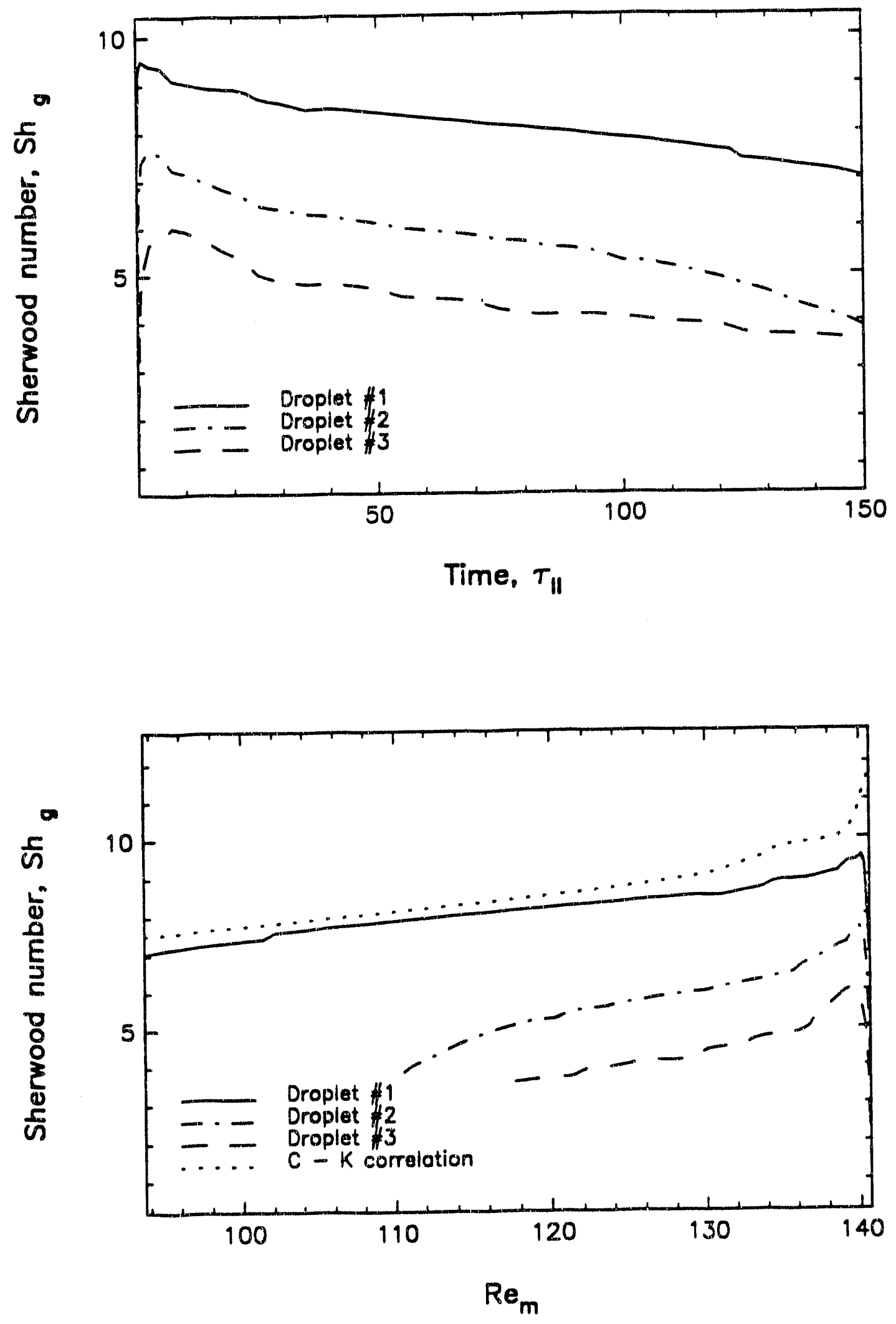


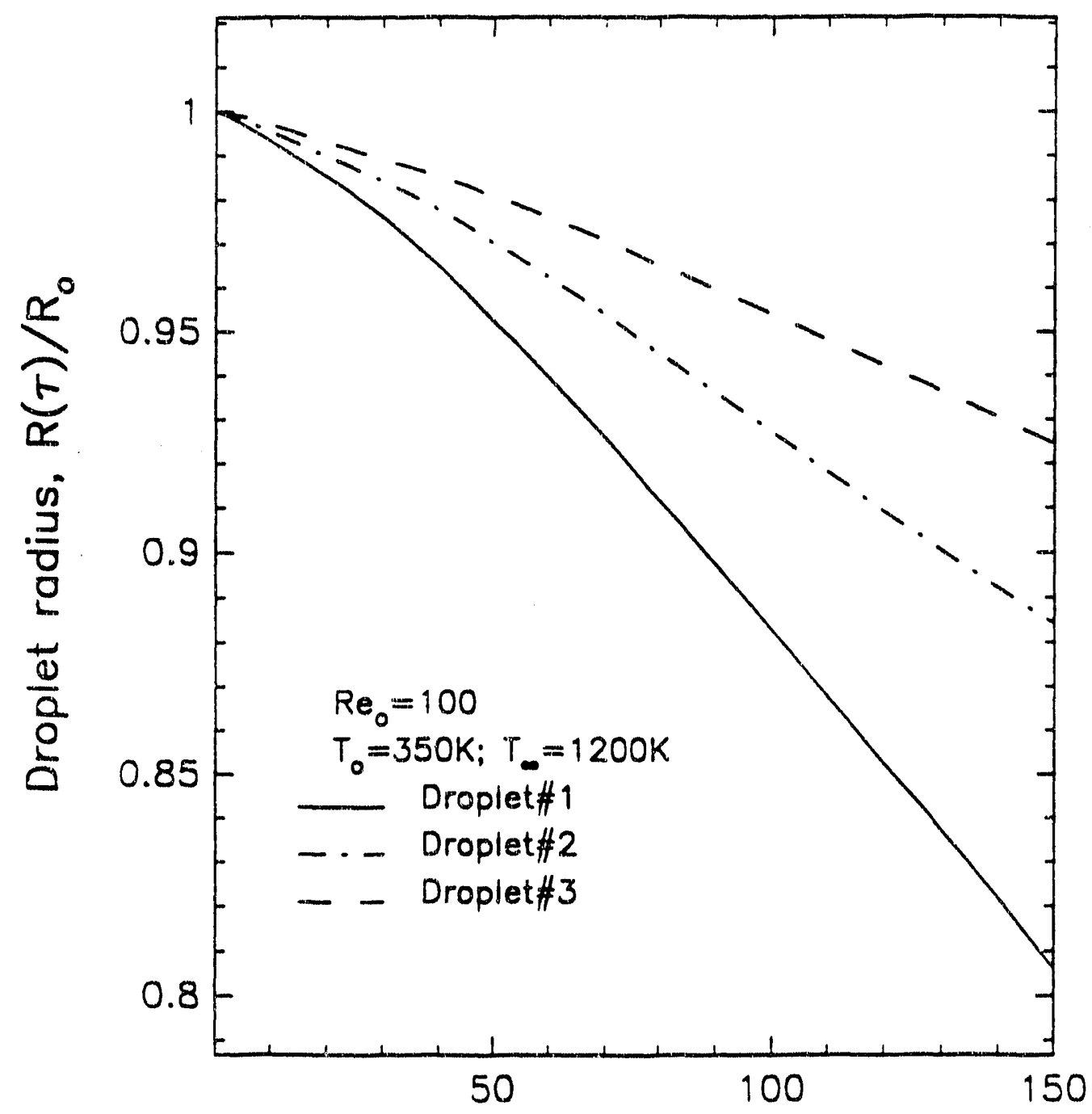

Time, $\tau_{\|}$ 


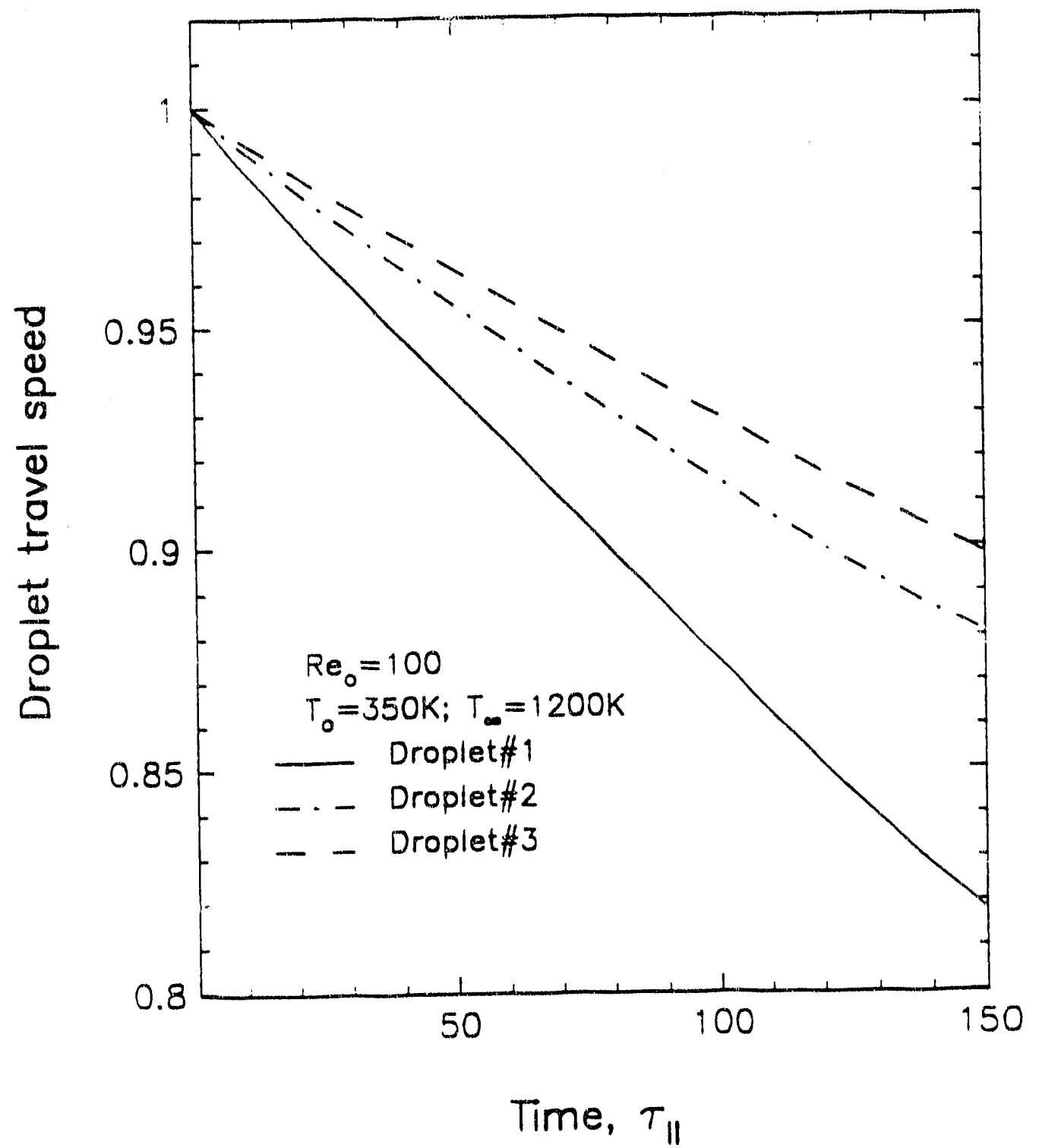




$$
\begin{array}{llll}
\text { case } & d_{i j}(\tau=0) & \\
\text { A } & d_{12}=6 & d_{23}=3 & v_{b}=0 \\
B & d_{12}=6 & d_{23}=3 & v_{b}=0.1 \\
C & d_{12}=6 & d_{23}=3 & \text { droplets }
\end{array}
$$

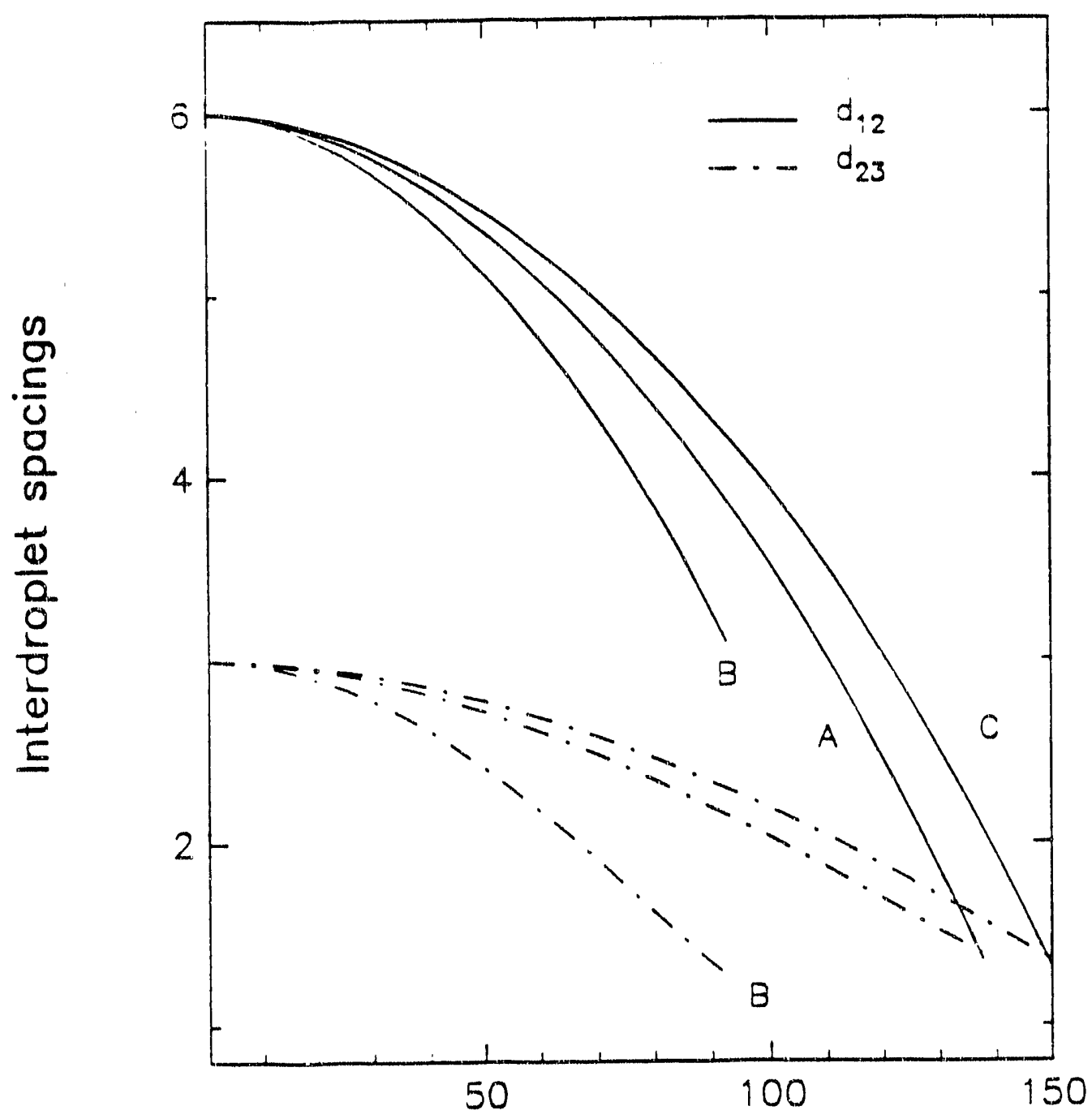

Time, $\tau_{\|}$ 

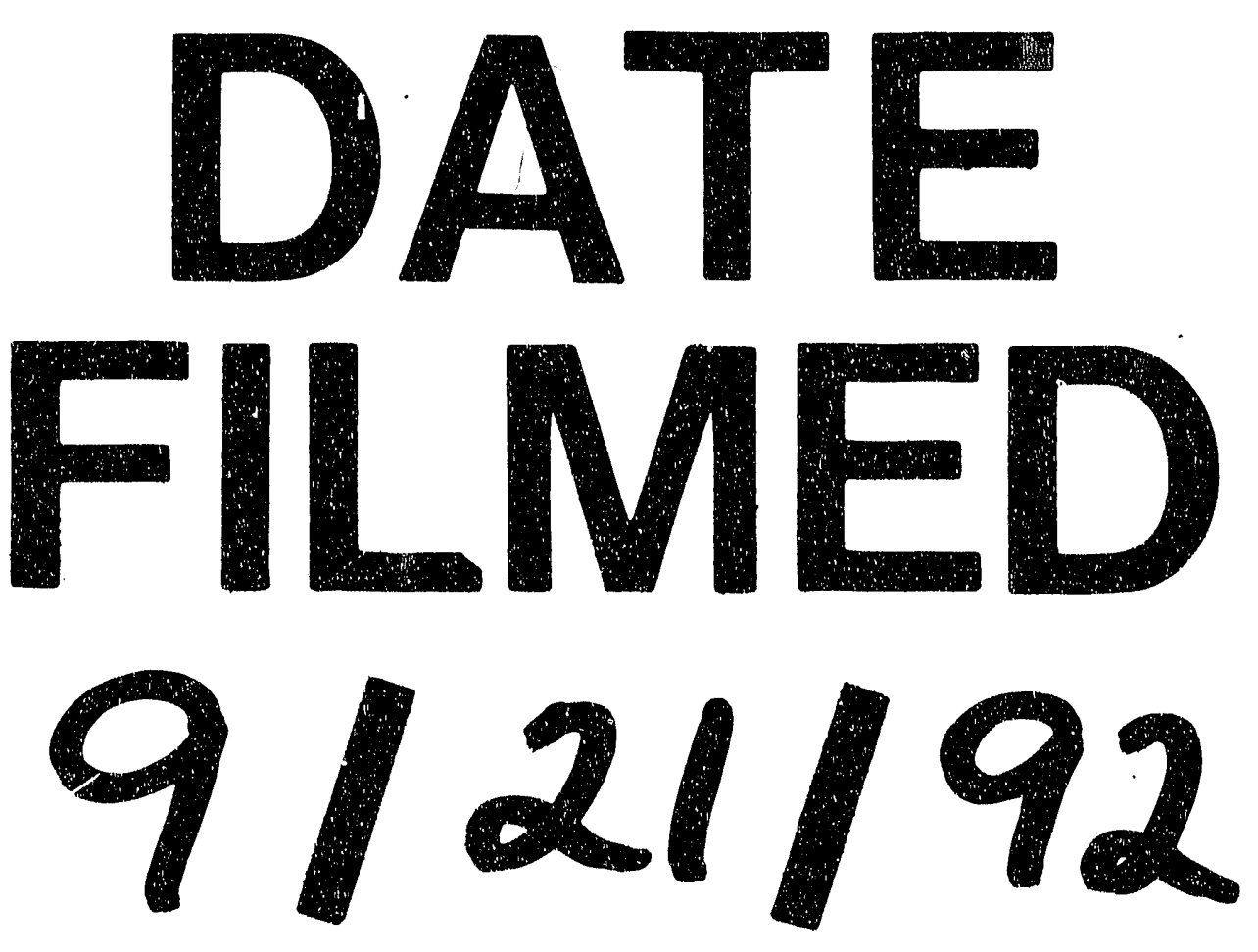
